\title{
Amyloid Precursor Protein Protects Neuronal Network Function after Hypoxia via Control of Voltage-Gated Calcium Channels
}

\author{
Dimitri Hefter, ${ }^{1}$ Martin Kaiser, ${ }^{1}$ Sascha W. Weyer, ${ }^{2}$ Ismini E. Papageorgiou, ${ }^{1}{ }^{\circ}$ Martin Both,,${ }^{1}$ Oliver Kann, ${ }^{1}$ \\ Ulrike C. Müller, ${ }^{2}$ and ${ }^{-}$Andreas Draguhn ${ }^{1}$ \\ ${ }^{1}$ Institute of Physiology and Pathophysiology and 2 Institute of Pharmacy and Molecular Biotechnology, Department of Bioinformatics and Functional \\ Genomics, University of Heidelberg, D-69210 Heidelberg, Germany
}

Acute cerebral ischemia and chronic neurovascular diseases share various common mechanisms with neurodegenerative diseases, such as disturbed cellular calcium and energy homeostasis and accumulation of toxic metabolites. A link between these conditions may be constituted by amyloid precursor protein (APP), which plays a pivotal role in the pathogenesis of Alzheimer's disease, but has also been associated with the response to acute hypoxia and regulation of calcium homeostasis. We therefore studied hypoxia-induced loss of function and recovery upon reoxygenation in hippocampal slices of mice lacking APP $\left(\mathrm{APP}^{-1-}\right)$ or selectively expressing its soluble extracellular domain (APPs $\alpha$-KI). Transient hypoxia disrupted electrical activity at the network and cellular level. In mice lacking APP, these impairments were significantly more severe, showing increased rise of intracellular calcium, faster loss of function, and higher incidence of spreading depression. Likewise, functional recovery upon reoxygenation was much slower and less complete than in controls. Most of these deficits were rescued by selective expression of the soluble extracellular fragment APPs $\alpha$, or by pharmacological block of L-type calcium channels. We conclude that APP supports neuronal resistance toward acute hypoxia. This effect is mediated by the secreted APPs $\alpha$-domain and involves L-type calcium channels.

Key words: APP; hippocampus; hypoxia; L-type calcium channels; neuroprotection; nifedipine

\section{Significance Statement}

Amyloid precursor protein (APP) is involved in the pathophysiology of Alzheimer's disease, but its normal function in the brain remains elusive. Here, we describe a neuroprotective role of the protein in acute hypoxia. Functional recovery of mouse hippocampal networks after transient reduction of oxygen supply was strongly impaired in animals lacking APP. Most protective effects are mediated by the soluble extracellular fragment APPs $\alpha$ and involve L-type calcium channels. Thus, APP contributes to calcium homeostasis in situations of metabolic stress. This finding may shed light on the physiological function of APP and may be important for understanding mechanisms of neurodegenerative diseases.

\section{Introduction}

The mammalian hippocampus is a pivotal brain region for spatial and declarative memory formation (Burgess et al., 2002). It is

\footnotetext{
Received Nov. 17, 2015; revised June 16, 2016; accepted June 19, 2016.

Author contributions: D.H., I.E.P., M.B., O.K., U.C.M., and A.D. designed research; D.H., M.K., and S.W.W. performed research;S.W.W. and U.C.M. contributed unpublished reagents/analytic tools; D.H., M.K., and A.D. analyzed data; D.H., M.K., and A.D. wrote the paper.

This work was supported by the Deutsche Forschungsgemeinschaft Grants MU 1457/9-1, MU 1457/9-2, and DRA $326 / 7-2$.

The authors declare no competing financial interests.

Correspondence should be addressed to Prof. Andreas Draguhn, Institute of Physiology and Pathophysiology, University of Heidelberg, Im Neuenheimer Feld 326, D-69210 Heidelberg, Germany. E-mail: andreas.draguhn@physiologie.uniheidelberg.de.

DOI:10.1523/JNEUROSCI.4130-15.2016

Copyright (C) 2016 the authors $\quad 0270-6474 / 16 / 368356-16 \$ 15.00 / 0$
}

among the first brain areas affected by Alzheimer's disease (AD) (Price et al., 2001) and is highly vulnerable to hypoxic insults (Schmidt-Kastner and Freund, 1991). Interestingly, patients who suffered hypoxic-ischemic brain injury have an increased risk of developing AD decades later in life (Zhang and Le, 2010). As a common mechanism, excessive intracellular calcium mediates both ischemia-induced neuronal death and neurodegeneration in $\mathrm{AD}$ (Berridge, 2010).

At the molecular level, multiple lines of evidence indicate a crucial role for the amyloid precursor protein (APP) in the pathogenesis of AD (O'Brien and Wong, 2011). The physiological function of this protein, however, is still poorly understood (Aydin et al., 2012). APP-deficient mice are largely healthy but show distinct cognitive deficits and altered synaptic plasticity in the hippocampus (Ring et al., 2007). Several lines of evidence suggest 
a neuroprotective role of APP in cellular stress response and aging (Kögel et al., 2012). Intracellular levels of APP rise under conditions of energy depletion (Hoyer et al., 2005), and the protein is upregulated following brain injury (Van den Heuvel et al., 1999). Moreover, APP-deficient mice show increased acute mortality following cerebral ischemia (Koike et al., 2012), whereas APP overexpression provides neuroprotection (Clarke et al., 2007). The soluble extracellular fragment APPs $\alpha$, generated by $\alpha$-secretase-mediated cleavage of APP, was shown to mediate protective effects in ischemic (Smith-Swintosky et al., 1994) and traumatic brain injury models (Thornton et al., 2006) and AD models in vivo (Fol et al., 2016), and to protect against hypoxic, hypoglycemic, and excitotoxic damage in vitro (Mattson et al., 1993; Milosch et al., 2014).

Although these data point toward some neuroprotective function of APP, the underlying mechanisms at the molecular, cellular, and network level remain unknown. Importantly, it is not clear whether this ubiquitously expressed protein exerts its protective effects via the vascular system or by direct interaction with neuronal functions (e.g., hypoxia-induced intracellular calcium increase). Also, the relative contribution of full-length APP versus its cleavage products remains debated. Most previous studies have focused on cell death, whereas the immediate impact of APP on cellular and network-level functions during metabolic stress is largely unknown. We therefore studied neuronal and network function of hippocampal networks in a model of transient hypoxia in vitro (Schurr et al., 1999), where cerebrovascular and other systemic factors are excluded. We report that functional recovery after transient hypoxia is strongly impaired in $\mathrm{APP}^{-1-}$ mice, indicating a direct neuroprotective role for APP in healthy brain tissue. This protective effect involves the soluble extracellular fragment of the protein (APPs $\alpha$ ) and reduction of calcium influx through L-type calcium channels. Our data shed light onto the enigmatic function of APP and constitute a new link between memory-related network activity, hypoxia, and neuronal calcium dynamics.

\section{Materials and Methods}

Animal handling and slice preparation. Procedures were in accordance with the German animal protection law and were approved by the state government of Baden-Wurttemberg (T-08/10). Wild-type (WT), $\mathrm{APP}^{-1-}$, and APPs $\alpha$-KI mice of both sexes at an age of 33-66 weeks were used for experiments. APP ${ }^{-1-}$ and APPs $\alpha$-KI mice were backcrossed at least six times onto a C57BL6 background. WT littermates were obtained from the last backcross of APP-KO mice. At this age, $\mathrm{APP}^{-/-}$mice show deficits in long-term potentiation (Ring et al., 2007). Generation of $\mathrm{APP}^{-1-}$ and APPs $\alpha$-KI mice was described previously (Li et al., 1996; Ring et al., 2007). Mice were anesthetized with $\mathrm{CO}_{2}(60 \%)$, decapitated, and the brain was quickly transferred into cooled ACSF $\left(1^{\circ} \mathrm{C}-4^{\circ} \mathrm{C}\right.$; saturated with $95 \% \mathrm{O}_{2} / 5 \% \mathrm{CO}_{2}$ [carbogen]). Composition of ACSF was (in $\mathrm{mm}$ ) as follows: $124 \mathrm{NaCl}, 3.0 \mathrm{KCl}, 1.8 \mathrm{MgSO}_{4}, 1.6 \mathrm{CaCl}_{2}, 10$ glucose, 1.25 $\mathrm{NaH}_{2} \mathrm{PO}_{4}$, and $26 \mathrm{NaHCO}_{3}$, pH 7.4. Horizontal slices of $450 \mu \mathrm{m}$ thickness from the mid to ventral portion of the hippocampus were cut on a Leica VT1000s or Leica V1200s vibratome (Leica Microsystems). Slices were maintained at $32^{\circ} \mathrm{C}-33^{\circ} \mathrm{C}$ in a modified Haas-type interface chamber for 3-4 h before starting recordings and were perfused with carbogen-saturated ACSF at $1.5-2 \mathrm{ml} / \mathrm{min}$. In electrophysiological experiments, the duration of hypoxia was $5 \mathrm{~min}$. For this period, gas supply was switched from carbogen to $95 \% \mathrm{~N}_{2} / 5 \% \mathrm{CO}_{2}$. This hypoxic period was followed by a $40 \mathrm{~min}$ recovery with carbogen. Mouse tales were kept at $-20^{\circ} \mathrm{C}$ and used for genotyping. All assessed genotypes matched the putative genotype.

Local field potential (LFP) recordings. LFPs were recorded with ACSFfilled borosilicate glass electrodes (Hilgenberg, tip diameter $\sim 9 \mu \mathrm{m}$ ) from the CA3 pyramidal cell layer (CA3p), CA1 pyramidal and dendritic cell layers (CA1p and CA1r, respectively). The Schaffer collateral was stimulated with $100 \mu$ s electrical pulses using a bipolar platinum/iridium stimulation electrode (Science Products). Electrode position was optimized for maximal population spike (PSs) at CA1p, and for a field EPSP (fEPSP) with as little contamination by the PS as possible at CA1r. Slices with insufficient sharp wave-ripple activity (frequency $<1 \mathrm{~Hz}$ ), PS amplitude $<2 \mathrm{mV}$, multiple PS responses to stimulation, variation in PS amplitude $>20 \%$ or continuously decreasing/increasing amplitude during baseline recording were discarded. There was no difference between genotypes in the incidence of insufficient baseline spontaneous activity or evoked responses. For monitoring effects of hypoxia, stimulation strength was adjusted to $50 \%$ of the maximum PS. During baseline and recovery, PS were elicited every $60 \mathrm{~s}$, whereas during the hypoxic period we stimulated every $30 \mathrm{~s}$ for higher temporal resolution. We also assessed paired pulse ratios with interspike intervals (ISIs) of 10, 50, and $280 \mathrm{~ms}$. The maximal PS amplitude was measured during baseline conditions and after $40 \mathrm{~min}$ of recovery from hypoxia.

Intracellular recordings. Intracellular recordings from CA1 pyramidal cells were performed using $60-110 \mathrm{M} \Omega$ borosilicate glass electrodes (Science Products) filled with $2 \mathrm{~m}$ potassium acetate and 1,5\% neurobiotine (Vector Laboratories). Following a stabilization period of $10 \mathrm{~min}$ current-free recording, the cell was characterized by 500 -ms-long current injections starting at $-400 \mathrm{pA}$ and increasing in steps of $100 \mathrm{pA}$ up to a current, which elicited a train of action potentials (APs). Only cells with a stable resting membrane potential, overshooting APs, stable AP amplitude, firing adaptation, AP waveforms with width $>600 \mu \mathrm{s}$, and low after-hyperpolarization (AHP) were classified as putative CA1 pyramidal neurons suitable for recording (Bähner et al., 2011). Notably, for intracellular recordings, more APP ${ }^{-1-}$ than WT cells had to be screened to find a "healthy" neuron according to these criteria, such that we cannot exclude a slight selection bias masking more severe deficits of $\mathrm{APP}^{-/-}$cells. Morphology and location of some of the recorded cells were evaluated using neurobiotine staining. All stained cells were located in CAlp and classified as pyramidal cells by microscopy. Input resistance and membrane time constant were calculated by 10 current pulses of $-200 \mathrm{pA}$ (duration $500 \mathrm{~ms}$, frequency $0.2 \mathrm{~Hz}$ ) under baseline conditions. Test pulses were repeated every $30 \mathrm{~s}$ during the time course of the experiment. AP properties were assessed by positive current injections. After 20 min of recovery following hypoxia, AP trains were elicited once again by positive current injection. Bridge balance was repeatedly adjusted during the experiment. Offset potentials were determined at the end of the experiment and subtracted from the recorded values.

Drugs. Drugs were applied into the bath solution $30 \mathrm{~min}$ before hypoxia induction. Experiments were continued if slices reached a steady state after drug application and aborted following spreading depression. Nifedipine (Sigma-Aldrich), and Bay K8644 (Tocris Bioscience) were aliquoted in DMSO (final concentration of $0.1 \%$ ) at $10 \mathrm{~mm}$ and stored at $4^{\circ} \mathrm{C}$ before final dilution in ACSF. All steps of the preparation, storage, and experiment were performed under light-protected conditions due to photosensitivity of the drugs. Similarly, APV (Tocris Bioscience) was stored in $60 \mathrm{~mm}$ aliquots at $-20^{\circ} \mathrm{C}$ before final dilution.

Data acquisition and analysis. LFP signals were amplified $100 \times($ EXT $10-2 \mathrm{~F}$ differential amplifier, NPI Electronic), low-pass filtered at $10 \mathrm{kHz}$, DC-filtered, and digitized at $20 \mathrm{kHz}$ for off-line analysis (1401 interface and Spike-2 data acquisition program; CED). Intracellular recordings were performed using an Axoclamp 900A amplifier (Molecular Devices). Sharp waves were detected in CA1p and CA3p and analyzed using custom-written MATLAB routines (Bähner et al., 2011). After automatized analysis, results underwent manual control.

Population spike amplitude was measured as the difference between the maximal negative peak (spike) and the mean of the positive peaks before and after the spike. fEPSP slope was calculated as the minimum first derivative of the evoked voltage response in CA1r and multiplied with -1 .

Intracellular data were analyzed using custom-written MATLAB routines. AP properties were calculated from current-evoked APs and analyzed as described by Bähner et al. (2011), with small alterations. The input resistance of cells was calculated from the difference between the median membrane potential at $100-450 \mathrm{~ms}$ of the 500 -ms-long, -200 
pA current injections and the resting median membrane potential before the current injection according to Ohm's law. All values were manually controlled for stimulation artifacts and spontaneous synaptic events.

Calcium imaging. For calcium measurements, the CA1 region was loaded with 1.5 mm Oregon Green BAPTA 1-AM (OGB-1-AM, Invitrogen) dye by multicell bolus pressure loading into the pyramidal layer of CA1 (Garaschuk et al., 2006). OGB-1 was dissolved in Pluronic F-127 (20\% solution in DMSO, Invitrogen) and diluted in $\mathrm{Ca}^{2+}$-free Ringer's solution (in mM as follows: $150 \mathrm{NaCl}, 2.5 \mathrm{KCl}, 10 \mathrm{HEPES}$ ). Dye solution was pressure-injected into the pyramidal layer of CA1 for $\sim 5 \mathrm{~min}$, using a patch electrode (borosilicate glass, $\sim 3 \mu \mathrm{m}$ tip diameter). Calcium imaging was started following $60 \mathrm{~min}$ incubation time after dye loading. During the loading process and imaging procedure, hippocampal network activity was monitored by field potential recordings. Images of a large field of view $(410 \times 410 \mu \mathrm{m})$ were collected using a custom-built fluorescence microscope with a CSU-X1 Nipkow-type spinning-disk (1800 rpm, Yokogawa) and sampled through a dry objective with long working distance (Olympus LM Plan FL N, $20 \times, 0.4 \mathrm{NA}$ ) by an electronmultiplying charge-coupled device (EMCCD) camera (Image EM C9100-13, Hamamatsu) at $31.9 \mathrm{~Hz}$. The combination of this type of microscope and the use of a Haas-type interface chamber enabled stable recording conditions over time (Reichinnek et al., 2010; Pfeiffer et al., 2014). OGB-1-AM was excited by $489 \mathrm{~nm}$ light generated by a laser (TopticaiBeam Smart). A dichroic mirror (486-491 nm, Yokogawa) and an emission filter (525 $\pm 18 \mathrm{~nm}$, Chroma) allowed separation between excitation and emission light. Imaging was performed under hypoxia until spreading depression occurred. The data were analyzed using ImageJ plug-ins (National Institutes of Health) and custom-written MATLAB routines (The MathWorks). We defined a region of interest (ROI) of $40 \times 40 \mu \mathrm{m}$ in the CAl pyramidal cell layer and obtained the average pixel intensity per image across each image sequence. Baseline fluorescence intensity was subtracted, and intensity values were calculated as percentage change from baseline conditions. Baseline was defined as average values from $60 \mathrm{~s}$ of continuous imaging time before induction of hypoxia. Significance of differences was tested by Wilcoxon's signed-rank test.

Histology. Slices were fixed at different time points after the experiment (see Results) using $4 \%$ PFA for $24-48 \mathrm{~h}$ on a shaker at $4^{\circ} \mathrm{C}$. They were then incubated in a $30 \%$ sucrose solution and cut into sections of 25 $\mu \mathrm{m}$ thickness on a cryotome (Leica CM1850, Leica Biosystems) at $-20^{\circ} \mathrm{C}$. For analysis, we chose $6-8$ slices from the middle portion of the specimen to exclude effects of the cutting procedure and of hypoxia at the surface/bottom of the original slice (Kann, 2011; Huchzermeyer et al., 2013). After cutting, slices were stored in a solution of v/v $31 \%$ ethylene glycol, $29 \%$ glycerin in PBS at $-20^{\circ} \mathrm{C}$. Stainings were performed after blocking background fluorescence with $0.3 \mathrm{~m}$ glycine for $1 \mathrm{~h}$. Before application of the primary antibodies (monoclonal mouse anti-NeuN, 1:500, mouse anti-parvalbumin, 1:500, both from EMD Millipore; and polyclonal rabbit anti-annexin $\mathrm{V}, 1: 250$, from Abcam), the sections were washed in PBS and treated with $10 \%$ normal goat serum $/ 0.3 \%$ Triton $\mathrm{X}-100$. Incubation with primary antibodies was continued for $36 \mathrm{~h}$ at $4^{\circ} \mathrm{C}$ under light protection. Before application of the secondary antibodies (Alexa-488 donkey anti-mouse, 1:500, from Invitrogen; and Cy3 goat anti-rabbit, 1:500, from Jackson ImmunoResearch Laboratories), the sections were washed in PBS and treated with $0.2 \%$ bovine albumin $/ 0.3 \%$ Triton X-100. Incubation with secondary antibodies was continued for $12 \mathrm{~h}$ at $4^{\circ} \mathrm{C}$ under light protection. For nuclear staining, sections were mounted with Fluoroshield (Sigma-Aldrich), containing DAPI. Widefield fluorescent microscopy was performed on a BX-61 system (Olympus), equipped with a 2 -axis computer-controlled stepping motor system (MicroBrightField), a mercury burner U-RFL-T (Olympus), a CCD camera F-View II (Olympus Soft Imaging Solutions), and a set of Olympus Uplan FI 49/NA 0.13, 109/NA 0.30, 209/NA 0.50, and 409/NA 0.75 objective lenses. In a custom-written MATLAB routine, a ROI was selected in the proximal CAlp. The experimenter was presented with 20 random, automatically detected nuclei from the ROI per section. For detection of the nuclei from the DAPI signal, a thresholding algorithm was applied (Smith et al., 1979). Then, cross-sectional areas of 20 randomly selected nuclei from the ROI were assessed by manually applying a circular fit to each nucleus' borders. Cells were evaluated for NeuN and annexin $\mathrm{V}$ stainings, respectively, and proportions of $\mathrm{NeuN}^{-}$and annexin $^{+}$cells in the section were calculated. The mean value for each recorded slice was calculated from the median values of 20 nuclei in each of the $6-8$ sections generated from this slice. During image acquisition and analysis, the experimenter was blinded toward experimental condition and genotype.

Statistics. Comparisons between the three genotypes were performed using one-way ANOVA with post hoc Tukey's Multiple Comparison Test used in case of $p<0.05$ in ANOVA. Comparisons between two groups (e.g., untreated slices vs drug-treated slices) were performed using the two-sided Mann-Whitney $U$ Test. To test for differences between two conditions within one group (e.g., baseline vs recovery), the Wilcoxon test for paired samples was applied. In these cases, data are presented as mean \pm SEM. For group comparisons, data are given as number of slices in different genotypes and number of mice from each genotype (e.g., $n=\mathrm{a} / \mathrm{b}$ slices from $\mathrm{c} / \mathrm{dWT}$ and APP ${ }^{-1-}$ mice, respectively). Probabilities of spreading depression were compared using the $\chi^{2}$ test for comparison of two proportions and Tukey's multiple comparison of proportions for more than two proportions. These data are presented as mean probability \pm Clopper-Pearson CIs. Linear correlations were analyzed using the least-squares linear regression and Pearson's linear correlation coefficient. Values after hypoxia were normalized by dividing through baseline values.

\section{Results}

\section{$\mathrm{APP}^{-/-}$slices show severely impaired excitability in CA1 after hypoxia}

Synaptic transmission between CA3 and CA1 was tested by stimulating the Schaffer collaterals in 44 slices from 14 wild-type mice (WT), 46 slices from 18 animals lacking $\operatorname{APP}\left(\mathrm{APP}^{-/-}\right)$, and 11 slices from 4 mice expressing only the extracellular fragment of APP (APPs $\alpha$-KI). Waveform and amplitude of fEPSP and PSs were largely identical between all groups (Fig. $1 A, B$ ). We then withdrew oxygen supply for $5 \mathrm{~min}$. Transient hypoxia rapidly suppressed PS (Fig. 1C) and fEPSPs (Fig. $1 F$ ) in all three genotypes. In some slices, a hypoxia-induced spreading depression (HSD) (Somjen, 2001) occurred under these conditions (see below). Although the acute effects of hypoxia were largely similar, recovery upon reoxygenation revealed striking differences between genotypes. In WT slices, amplitudes of PS, and slopes of fEPSPs recovered within $\sim 15-20 \mathrm{~min}$, followed by a potentiation of responses to $\sim 125 \pm 11 \%$ of baseline values (mean \pm SEM, $n=13$ slices from 7 mice). In contrast, slices from $\mathrm{APP}^{-1-}$ mice expressed a lasting deficit in recovery of PS (Fig. $1 C, D$ ), which remained at $\sim 57 \pm 9 \%$ of baseline after $\sim 20$ min of reoxygenation $(n=21$ slices from 9 mice; $p=0.00007$, one-way ANOVA). After $40 \mathrm{~min}$ of recovery, the maximum PS amplitude was assessed (Fig. 1E). Maximum PS in WT slices regained $\sim 99 \pm 6 \%$ of baseline values, whereas $\mathrm{APP}^{-1-}$ slices showed an incomplete recovery with $\sim 71 \pm 6 \%$ of baseline ( $p=0.0042$, one-way ANOVA). Slopes of fEPSPs recovered fully and similarly in both genotypes $(128 \pm 13 \%$ in wild-type $[n=7$ slices from 5 mice $]$ vs $98 \pm 11 \%$ in $\mathrm{APP}^{-1-}[n=9$ slices from 6 mice]; Fig. $1 F, G)$. PS in slices from APPs $\alpha$-KI mice recovered almost to baseline levels $(97 \pm 13 \%, n=11$ slices from 4 mice). Thus, intrinsic neuronal excitability remained impaired in tissue lacking APP despite normal synaptic excitation. Accordingly, excitation-spike-coupling (E/S coupling) remained decreased in $\mathrm{APP}^{-1-}$ slices (Fig. $1 H$ ).

\section{Block of L-type calcium channels, but not NMDA receptors, restores posthypoxic deficits in $\mathrm{APP}^{-/-}$mice}

Hypoxia causes strong increases of intracellular calcium concentration in neurons (Lobner and Lipton, 1993). Major sources of 
A
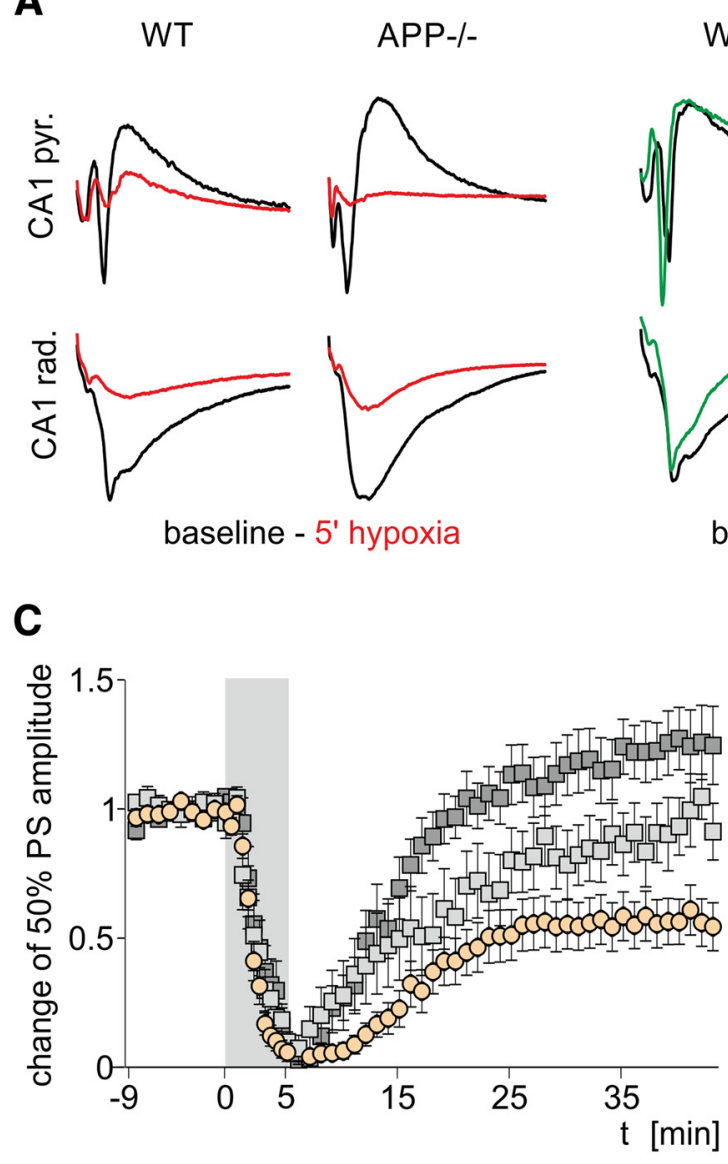

F

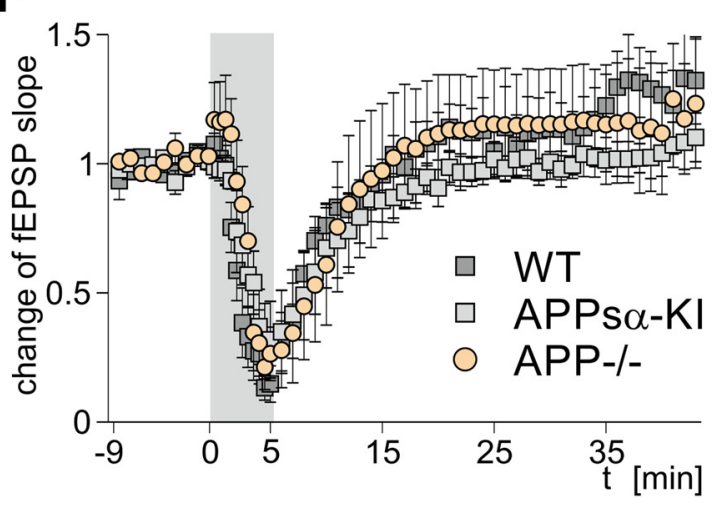

WT

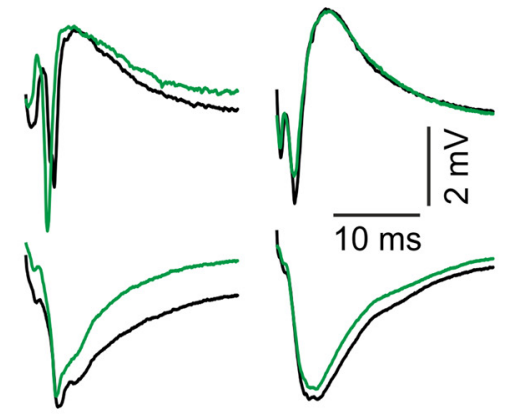

baseline $-25^{\prime}$ recovery

B
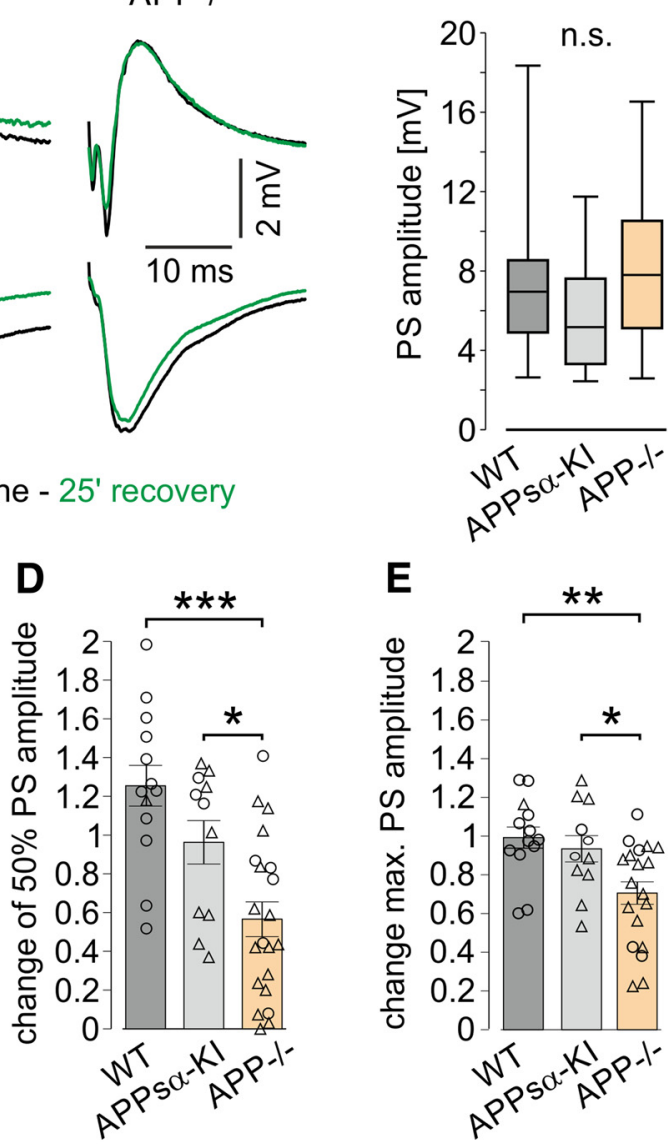

$\mathbf{G}$

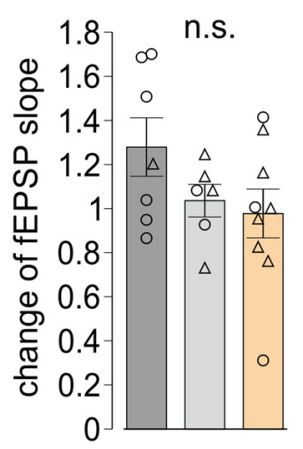

E

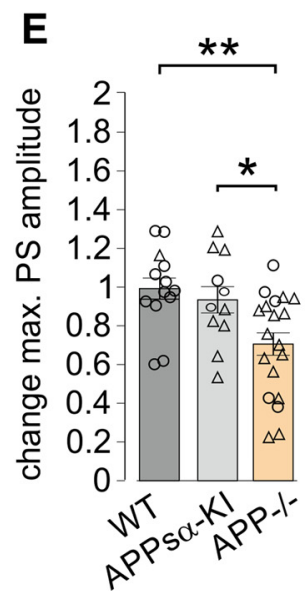

H

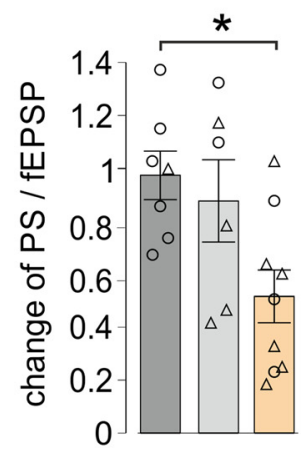

Figure 1. Unaltered baseline evoked responses but severely impaired excitability after hypoxia in slices from APP ${ }^{-1-}$ mice compared with WT and APPs $\alpha$-KI. $A$, Representative traces of evoked responses in the CA1 pyramidal (top row) and dendritic (bottom row) cell layers in WT and APP ${ }^{-1-}$ slices during baseline (black), hypoxia (red), and after recovery (green). $\boldsymbol{B}$, Baseline maximum PS amplitude. $\boldsymbol{C}, \boldsymbol{F}$, Change of PS amplitude $(\boldsymbol{C})$ and the fEPSP slope $(\boldsymbol{F})$ in the time course of the experiment. Gray area represents the period of hypoxia. Values are mean \pm SEM. $\boldsymbol{D}$, Recovery of the half-maximum PS amplitude $30-40$ min after hypoxia. $p=0.00007$ (one-way ANOVA). $\boldsymbol{E}$, Recovery of the maximum PS amplitude 40 min after hypoxia. $p=0.0042$ (one-way ANOVA). $G$, Recovery of the fEPSP after hypoxia. $p=0.16$ (one-way ANOVA). $\boldsymbol{H}$, Change of E/S coupling (PS/fEPSP) after hypoxia. $p=0.0183$ (one-way ANOVA). $\boldsymbol{D}, \boldsymbol{E}, \mathbf{G}, \boldsymbol{H}$, Circles represent single experiments without HSD. Triangles represent experiments where HSD occurred. ${ }^{*} p<0.05$ (one-way ANOVA with posthoc Tukey's Multiple Comparison Test). ${ }^{* *} p<0.01$ (one-way ANOVA with post hoc Tukey's Multiple Comparison Test). ${ }^{* * *} p<0.001$ (one-way ANOVA with posthoc Tukey's Multiple Comparison Test). n.s., Not significant. Baseline PS: $n=44 / 46 / 11$ slices from 14/18/4 WT, APP ${ }^{-/-}$, and APPs $\alpha-$ KI mice, respectively. Recovery of PS: $n=13 / 21 / 11$ slices from 7/9/4 WT, APP ${ }^{-1-}$ and APPs $\alpha$-KI mice, respectively. Recovery of fEPSP and E/S coupling: $n=7 / 9 / 6$ slices from 5/6/3 WT, APP ${ }^{-1-}$, and APPs $\alpha$-KI mice, respectively.

calcium influx from the extracellular space are L-type voltagegated calcium channels (LTCCs) and NMDA receptors. Both channels have successfully been targeted to alleviate neuronal damage after hypoxia (Zhang et al., 2002). APP has been reported to interact with both LTCC (Yang et al., 2009) and NMDA receptors (Cousins et al., 2009). We therefore repeated the experiments in presence of specific blockers of these channels. Indeed, appli- cation of the LTCC-blocker nifedipine $(10 \mu \mathrm{M})$ before and during hypoxia abolished the difference between slices from WT and $\mathrm{APP}^{-1-}$ mice. Population spikes recovered to $113 \pm 5 \%$ and $106 \pm 15 \%$ of baseline in WT and $\mathrm{APP}^{-1-}$ mice, respectively ( $n=10 / 12$ slices from $3 / 5$ mice, respectively; $p=0.77$, two-sided Mann-Whitney $U$ Test; Fig. $2 A, B)$. In contrast, the NMDA receptor blocker APV $(60 \mu \mathrm{M})$ had no effect on the delayed recovery 
A

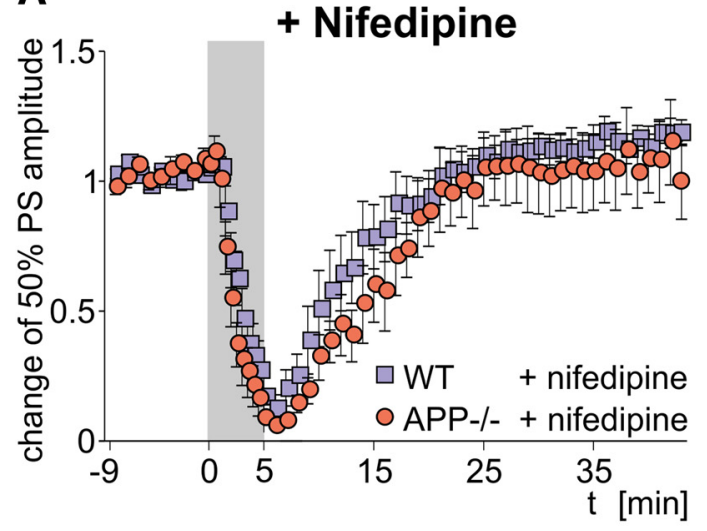

C

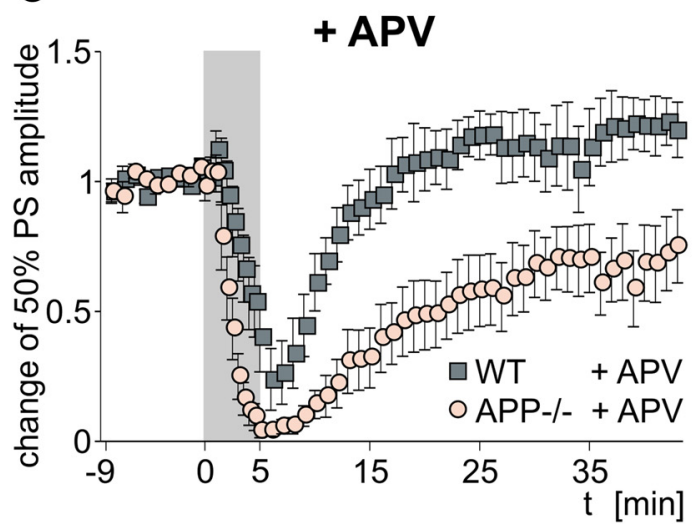

B

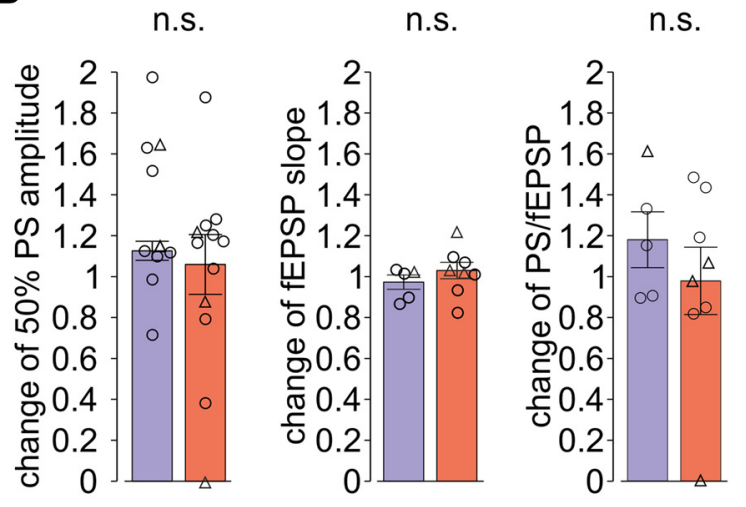

D

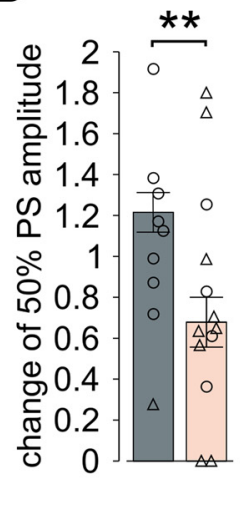

after recovery of hypoxia

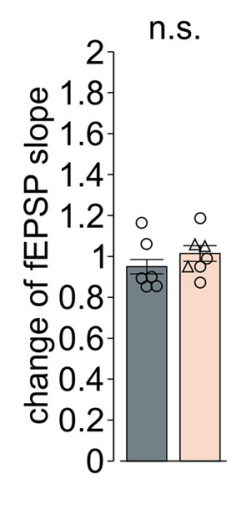

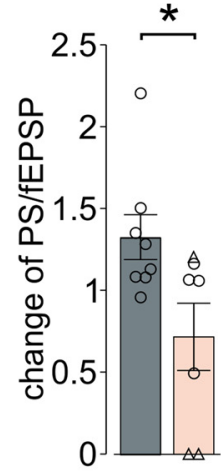

Figure 2. L-type calcium channel blocker nifedipine (10 $\mu \mathrm{M})$, but not NMDA receptor blocker APV (60 $\mu \mathrm{M})$, rescues PS recovery in APP ${ }^{-1-}$ slices. $\boldsymbol{A}$, $\boldsymbol{C}$, Time courses of PS amplitude in nifedipine-treated $(\boldsymbol{A})$ and APV-treated $(\boldsymbol{C})$ slices, respectively. $\boldsymbol{B}, \boldsymbol{D}$, Recovery of evoked responses $30-40$ min after hypoxia in presence of nifedipine $(\boldsymbol{B})$ and APV $(\boldsymbol{D})$, respectively. Left, PS amplitude. Middle, fEPSP slope. Right, E/S coupling. Circles represent single experiments without HSD. Triangles represent experiments where HSD occurred. * $p=0.0401$ (tw0-sided MannWhitney UTest). ${ }^{* *} p=0.0077$ (two-sided Mann-Whitney U Test). Nifedipine experiments: $n=10 / 12$ slices from $3 / 5$ WT and APP $-/-$ mice, respectively. APV experiments: $n=11 / 13$ slices from 4/4 WT and APP ${ }^{-1-}$ mice, respectively. n.S., Not significant.

of APP ${ }^{-1-}$ slices. Similar to drug-free ACSF, PS amplitude remained decreased after transient hypoxia ( $p=0.0077$, two-sided Mann-Whitney $U$ Test), whereas fEPSP recovered fully (Fig. $2 C, D)$. Thus, calcium influx through voltage-gated calcium channels is a key mechanism underlying the increased hypoxia sensitivity of $\mathrm{APP}^{-1-}$ tissue. Increasing basal activity of L-type calcium channels with BayK8644 $(4 \mu \mathrm{M})$ caused no difference in PS recovery ( $114 \pm 15 \%$ of baseline) or HSD probability (HSD in $1 / 7$ slices) in WT. Application of DMSO (0.1\%) alone, applied in 8 slices from $3 \mathrm{APP}^{-1-}$ mice, had no influence on the recovery of PS ( $60 \pm 19 \%$ of baseline) or on HSD occurrence (HSD in $6 / 8$ slices), thus ruling out a protective effect of the solvent in our experiments. None of the drugs exerted any relevant effect on evoked responses under normal oxygenation conditions (data not shown).

\section{Increased short-term facilitation in $\mathrm{APP}^{-/-}$tissue following hypoxia}

We assessed short-term plasticity by paired pulse stimulation at intervals (ISI) of 10, 50, and $280 \mathrm{~ms}$ and found no major differences between genotypes, with most slices showing 1.2- to 1.5fold facilitation of the second response at ISI of $50 \mathrm{~ms}$ (Fig. $3 A, C)$. Following hypoxia, however, $\mathrm{APP}^{-1-}$ slices showed a significantly increased paired-pulse facilitation of PS at ISI of $50 \mathrm{~ms}$ compared with WT (Fig. $3 B ; n=13 / 21$ slices from 7/9 WT and $\mathrm{APP}^{-/-}$mice, respectively; $p=0.014$, Mann-Whitney $U$ Test), with unaltered short-term plasticity of fEPSPs (Fig. 3D). At ISI of 10 and $280 \mathrm{~ms}$, no alterations of paired pulse ratios were observed after hypoxia. Application of nifedipine and APV alone did not have a significant effect on short-term plasticity. Following recovery from hypoxia, however, the facilitation of PS PPR at ISI of $50 \mathrm{~ms}$ in $\mathrm{APP}^{-1-}$ was abolished in slices treated with either of the drugs (Fig. 3E). In nifedipine-treated $\mathrm{APP}^{-1-}$ slices, the PPR of fEPSP at ISI of $50 \mathrm{~ms}$ was reduced following hypoxia (Fig. $3 E$; $n=$ $5 / 8$ slices from $3 / 4$ mice; $p=0.011$, Mann-Whitney $U$ Test). Finally, we correlated the change in short-term plasticity (PPR of PS at $50 \mathrm{~ms}$ ) with the change in excitability of the CA1 network, measured as the change in efficacy of stimulation-evoked population-spikes after hypoxia. Indeed, these parameters were clearly correlated in $\mathrm{APP}^{-1-}$ tissue, in line with the different excitation-spike coupling in mice lacking APP (Fig. 3G).

\section{Altered cellular properties and impaired recovery from hypoxia of CA1 pyramidal cells in APP ${ }^{-/-}$slices}

We next searched for cellular correlates of the increased vulnerability toward hypoxia in $\mathrm{APP}^{-1-}$ slices. Intracellular recordings from CA1 pyramidal cells revealed a significantly depolarized resting membrane potential in $\mathrm{APP}^{-1-}$ mice compared with $\mathrm{WT}$ $(-63.3 \pm 2.4 \mathrm{mV}[n=15$ cells from 6 mice $]$ vs $-73.3 \pm 1.4 \mathrm{mV}$ [ $n=15$ cells from 9 mice], respectively; $p=0.0103$, one-way ANOVA, Figure $4 A$ ). Input resistance (Fig. $4 B$ ) and membrane time constant (data not shown) did not vary significantly be- 
A

baseline paired pulse ratios at $\mathbf{5 0}$ ms ISI

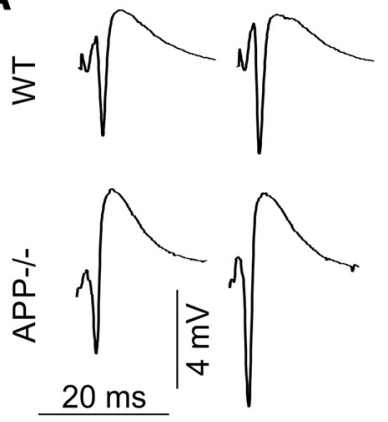

C
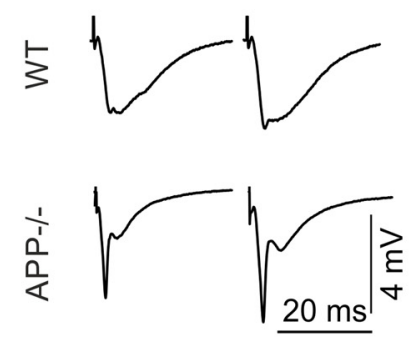

E

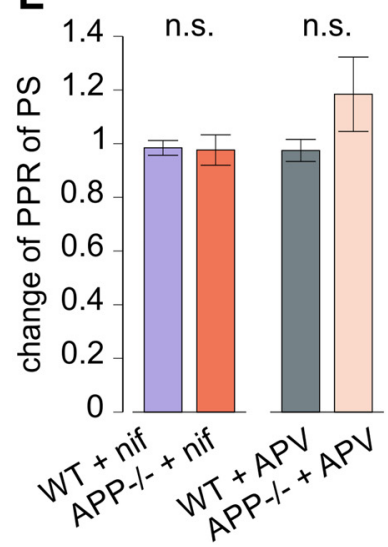

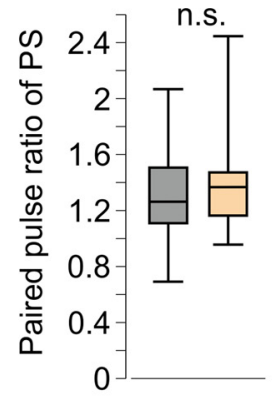

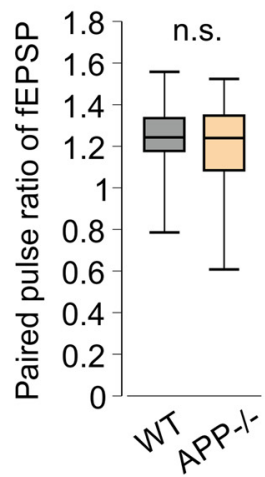

$\mathbf{F}$

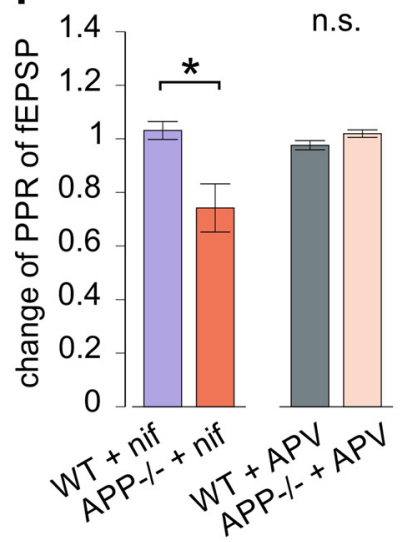

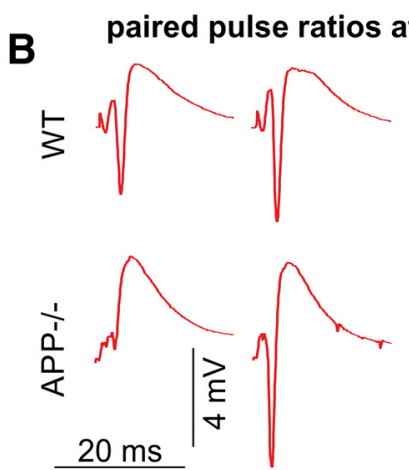
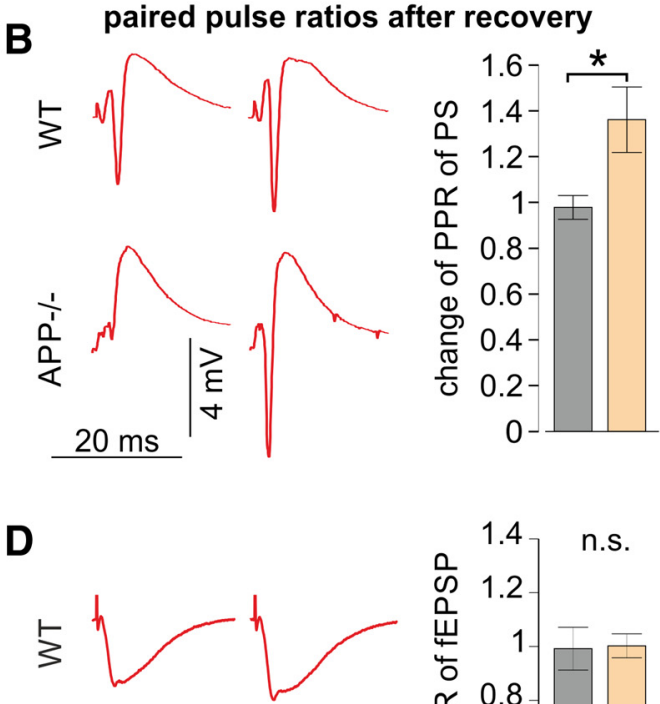

G

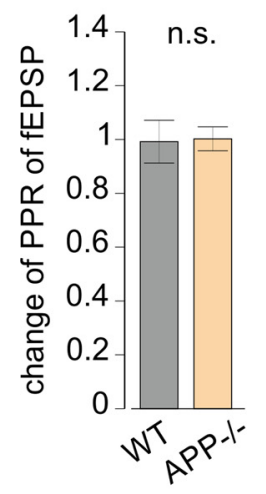

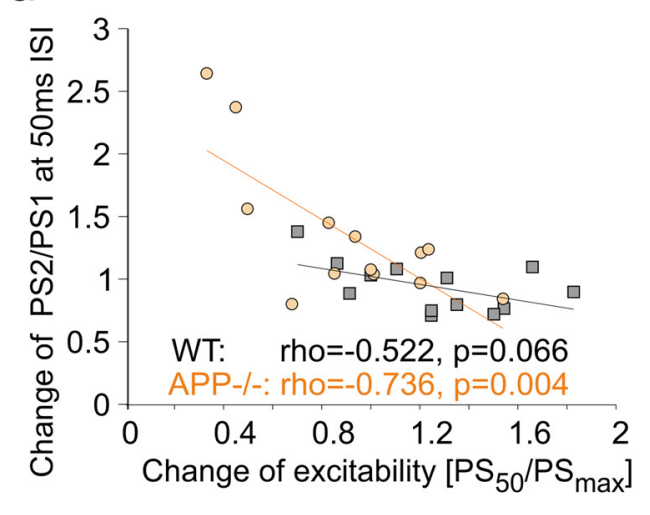

Figure 3. Altered short-term plasticity in APP ${ }^{-1-}$ slices after hypoxia. $A-D$, Paired pulse stimulation with $50 \mathrm{~ms}$ ISI during baseline recording $(A, C)$ and after recovery of hypoxia $(B, D)$ in WT and $\mathrm{APP}^{-/-}$slices. Left, Example responses. Right, baseline PPR $(\boldsymbol{A}, \boldsymbol{C})$ and change of PPR after hypoxia $(\boldsymbol{B}, \boldsymbol{D})$. $\boldsymbol{A}$, Baseline PPR of PS (44/46 slices from $14 / 18 \mathrm{WT}$ and APP ${ }^{-/-}$mice, respectively; $p=0.52$, two-sided Mann-Whitney U Test). $\boldsymbol{B}$, Change of PPR of PS (13/21 slices from 7/9 WT and APP ${ }^{-1-}$ mice, respectively; $p=0.014$, two-sided Mann-Whitney U Test). C, Baseline PPR of fEPSP (21/24 slices from 11/13 WT and APP ${ }^{-1-}$ mice, respectively; $p=0.86$, two-sided Mann-Whitney U Test). D, Change of PPR of fEPSP ( $7 / 9$ slices from $5 / 6 \mathrm{WT}^{-}$and APP ${ }^{-1-}$ mice, respectively; $p=0.83$, two-sided Mann-Whitney U Test). $\boldsymbol{E}$, Change of PPR of PS after hypoxia in nifedipine-treated (10/12 slices from 3/5 WT and APP ${ }^{-1-}$ mice, respectively; $p=0.38$, two-sided Mann-Whitney U Test) and APV-treated slices (11/13 slices from 4/4 WT and APP ${ }^{-1-}$ mice, respectively; $p=0.20$, two-sided Mann-Whitney U Test). $F$, Change of PPR of fEPSP after hypoxia in nifedipine-treated (5/8 slices from 3/4 WT and APP ${ }^{-I-}$ mice, respectively; $p=0.011$, two-sided Mann-Whitney UTest) and APV-treated (10/7 slices from 3/3 WT and APP ${ }^{-/-}$mice, respectively;

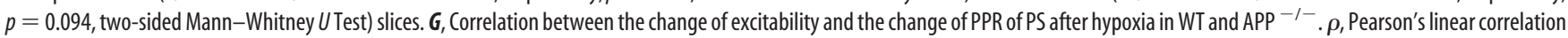
coefficient; $p, p$ value for Pearson's correlation using Student's distribution for transformation of correlation. n.s., Not significant. ${ }^{*} p<0.05$, two-sided Mann-Whitney $U$ Test.

tween groups. Likewise, membrane capacitance did not differ between cells from WT and $\mathrm{APP}^{-1-}$ mice. However, capacitance in cells from $\mathrm{APP}^{-1-}$ mice was slightly lower than in APPs $\alpha$-KI

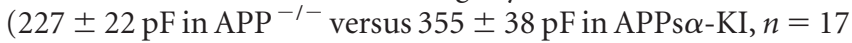
cells from 6 mice) and nifedipine-treated APP ${ }^{-1-}$ cells $(358 \pm 46$ pF; $n=10$ cells from 5 mice; Fig. $4 C ; p=0.0088$, one-way ANOVA). In most cells, hypoxia induced an initial hyperpolarization (Fig. $4 D$, top). At $2 \mathrm{~min}$ following hypoxia, this negative shift of membrane potential was significantly larger in $\mathrm{APP}^{-1-}$ cells compared with both other genotypes. Again, this difference was abolished by nifedipine (Fig. $4 D$, middle; $p=0.008$, one-way
ANOVA), which rendered the membrane potential of APP ${ }^{-1-}$ cells remarkably stable ( 5 of 6 cells). During hypoxia, most cells experienced a transient decrease of input resistance and membrane time constant without significant differences between genotypes (data not shown). Stable recordings for at least $20 \mathrm{~min}$ following hypoxia could be obtained from 6/15 WT cells, 5/10 APPs $\alpha$-KI, 6/11 $\mathrm{APP}^{-/-}$, and 6/10 nifedipine-treated neurons. Some of these cells developed HSD without clear differences between groups $\left(2 / 6,4 / 5,2 / 6\right.$, and $1 / 6$ in WT, APPs $\alpha$-KI, APP ${ }^{-/-}$ and nifedipine-treated $\mathrm{APP}{ }^{-1-}$ slices, respectively). In slices with $\mathrm{HSD}$, cells quickly depolarized up to $-5 \mathrm{mV}$, but mostly regained 
A
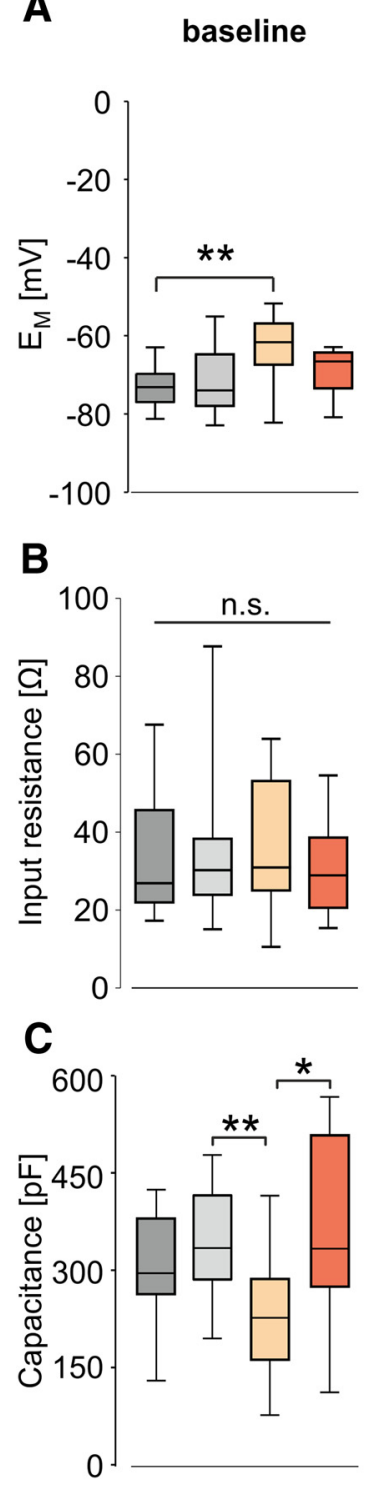

D
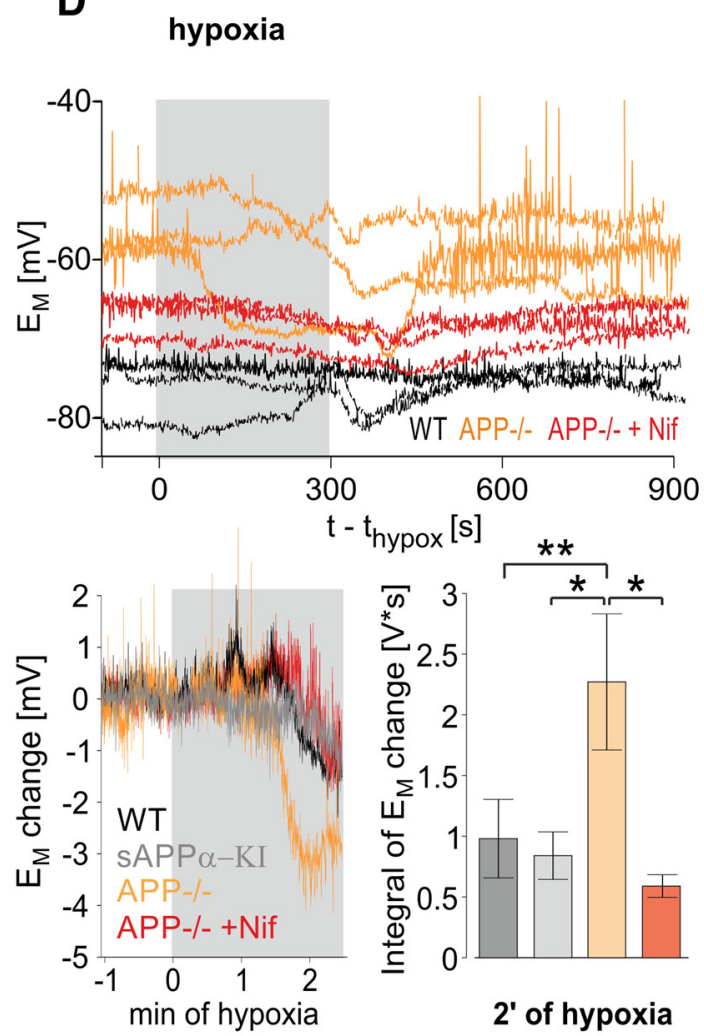

hypox $[\mathrm{s}]$
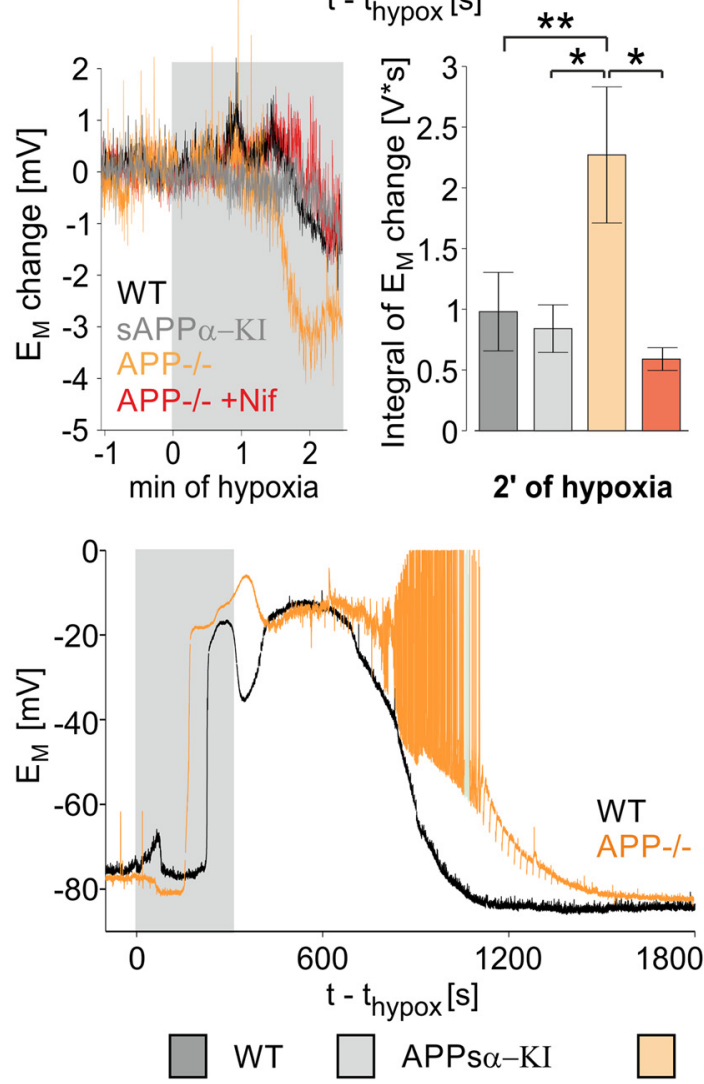

E

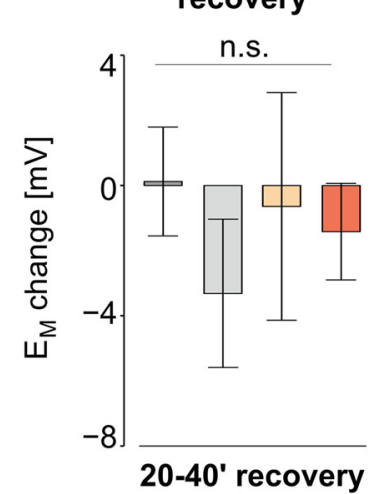

F

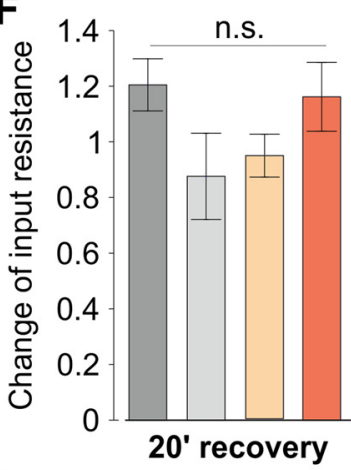

G

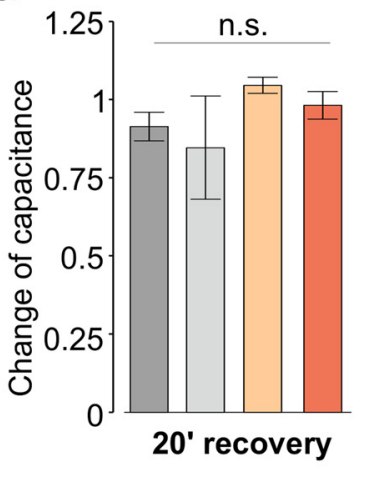

APP-/-

APP-/- +Nif

Figure 4. Depolarized resting membrane potential of CA1 pyramidal neurons in APP ${ }^{-/-}$mice and accelerated hyperpolarization in response to hypoxia. $A$, Resting membrane potential of CA1 pyramidal neurons in WT (dark gray), APPs $\alpha$-KI (light gray), APP ${ }^{-1-}$ (orange), and nifedipine-treated APP ${ }^{-1-}$ (crimson) tissue at baseline conditions. $p=0.0103$ (one-way ANOVA). $B$, Input resistance during baseline, calculated from a series of negative current injections. $p=0.67$ (one-way ANOVA). C, Membrane capacitance. $p=0.0088$ (one-way ANOVA). $\boldsymbol{D}$, Top, Resting membrane potential of each three WT (black), APP ${ }^{-1-}$ (orange), and nifedipine-treated APP ${ }^{-1-}$ (crimson) cells without occurrence of spreading depression during hypoxia and early recovery. APs are truncated; time points of current injection are cut out. Middle left, Change of the mean resting membrane potential during the first $150 \mathrm{~s}$ of hypoxia. Middle right, Integral of the resting membrane potential change between baseline and 2 min of hypoxia. $p=0.008$ (one-way ANOVA). Bottom, Membrane potential in a WT (black) and an APP ${ }^{-1-}$ cell (orange) in slices with spreading depression. APs are truncated at $0 \mathrm{mV}$; time points of current injections are cut out. $\boldsymbol{E}$, Change of resting membrane potential after recovery of hypoxia. $p=0.34$ (one-way ANOVA). $\boldsymbol{F}$, Change of input resistance after recovery. $p=0.22$ (one-way ANOVA). G, Change of membrane capacitance after recovery. $p=0.36$ (one-way ANOVA). $A-C, n=15 / 17 / 15 / 10$ cells from 6/6/9/5 WT, APPs $\alpha-\mathrm{KI}_{1} \mathrm{APP}^{-1-}$, and APP ${ }^{-I-}$ mice in the presence of nifedipine, respectively. $E-G, n=6 / 5 / 5 / 6$ cells from 4/4/4/4 mice, respectively. ${ }^{*} p<0.05$ (one-way ANOVA with $p o s t$ hoc Tukey's Multiple Comparison Test). ${ }^{* *} p<0.01$ (one-way ANOVA with post hoc Tukey's Multiple Comparison Test). ${ }^{* * *} p<0.001$ (one-way ANOVA with post hoc Tukey's Multiple Comparison Test). n.s., Not significant.

their membrane potential following reoxygenation (see also Fig. $4 D$, bottom). Recovery of membrane potential was unaltered between genotypes, with larger variation in $\mathrm{APP}^{-1-}$ cells (Fig. $4 E$ ). Input resistance (Fig. $4 F$ ) and membrane capacitance (Fig. $4 G$ ) also recovered similarly in all groups.

We then compared waveforms of APs between neurons from WT and APP-deficient mice before and after hypoxia. Amplitude and rate of rise were lower in $\mathrm{APP}^{-1-}$ compared with WT and
APPs $\alpha$-KI but adopted control values in the presence of $10 \mu \mathrm{M}$ nifedipine (Fig. 5A-C, top, 15/14/12/10 cells from 6/6/9/5 WT, $\mathrm{APPs} \alpha-\mathrm{KI}, \mathrm{APP}^{-1-}$ mice with/without nifedipine-application, respectively). Following reoxygenation, cells from $\mathrm{APP}^{-1-}$ mice showed slightly reduced amplitude and rate of rise of APs compared with prehypoxic conditions. This effect was fully rescued by nifedipine (Fig. $5 A-C$, bottom, $6 / 4 / 5 / 6$ cells from $4 / 4 / 4 / 4$ mice, respectively). Remarkably, cells from APPs $\alpha$-KI did not 
A

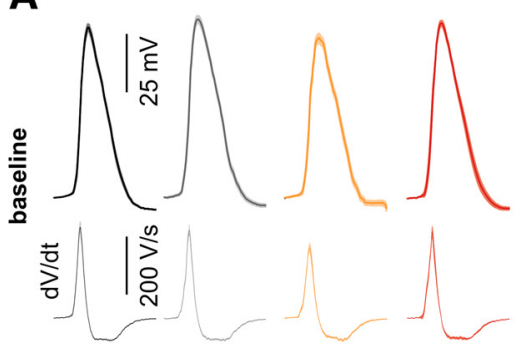

WT APPs $\alpha-$ KI APP-/- APP-/-+Nif

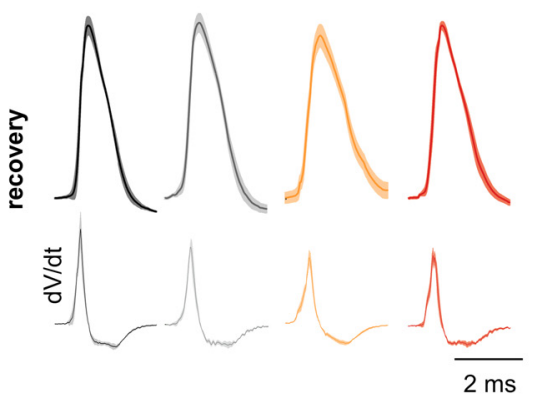

E WT

APP-I-

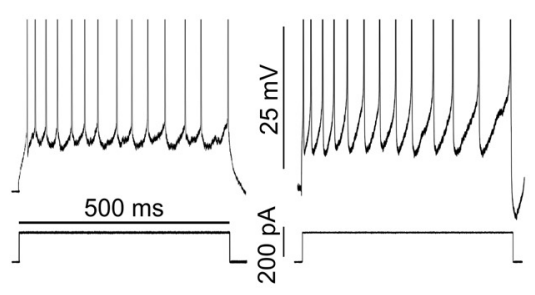

I
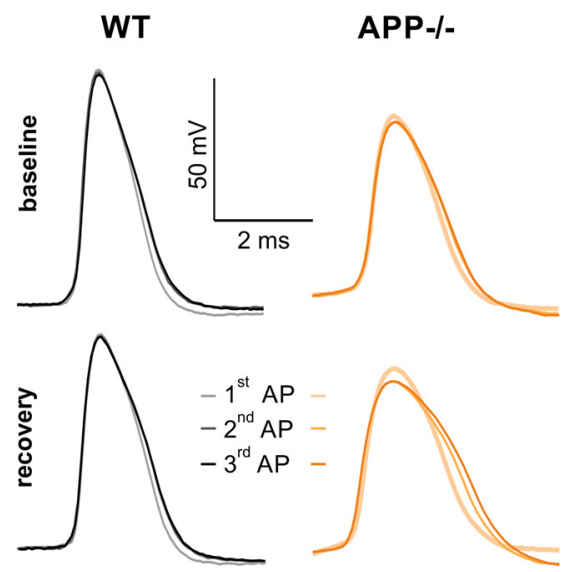

WT

APP-I-
B
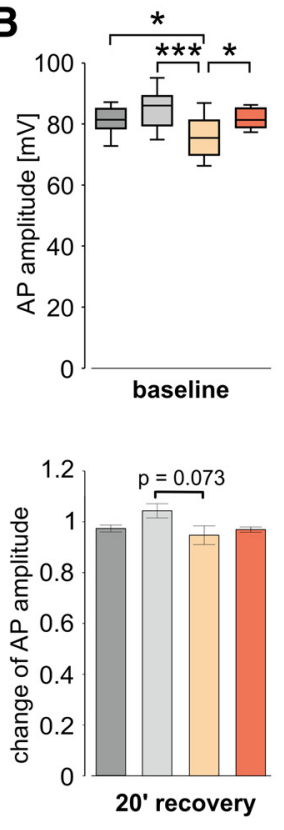

F
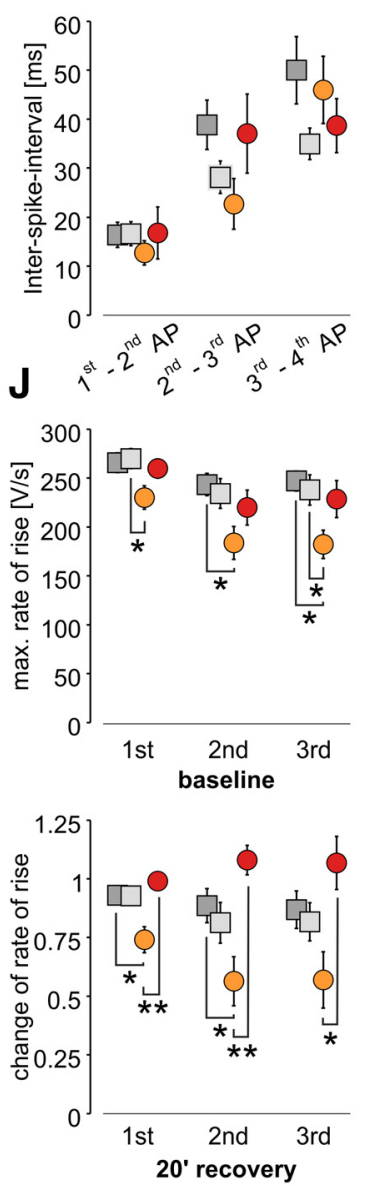

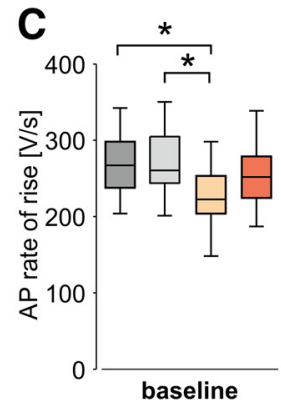

D
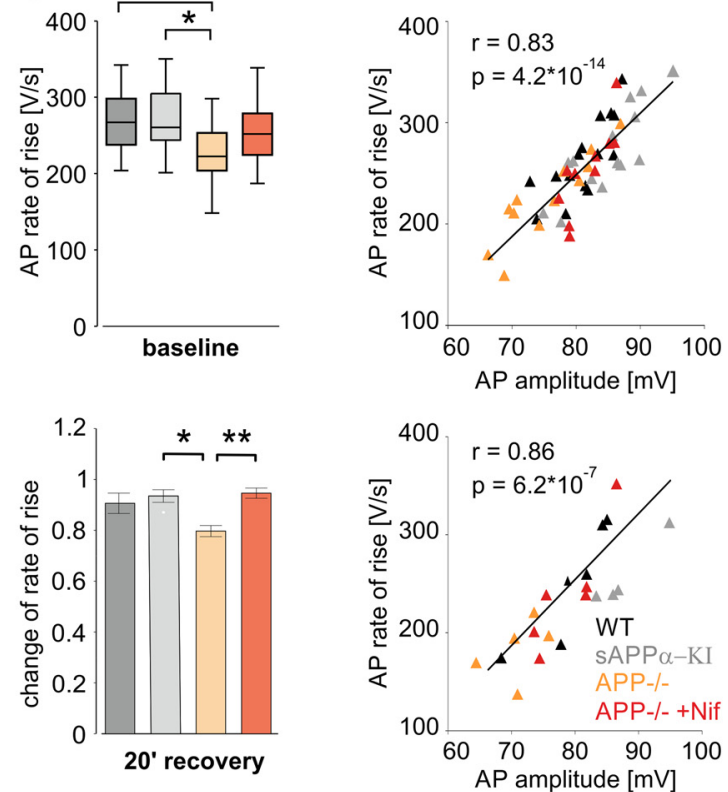

G
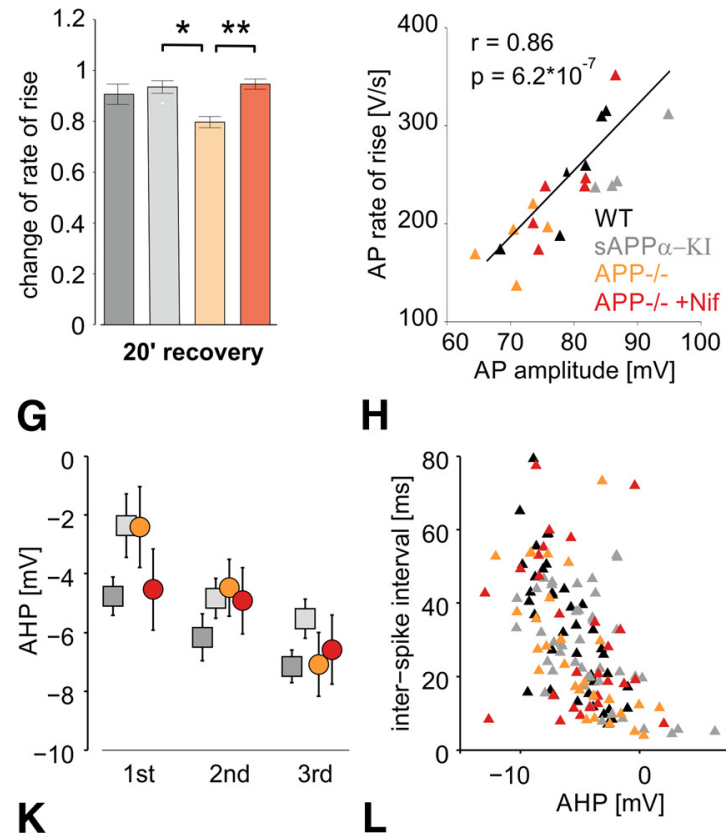

H
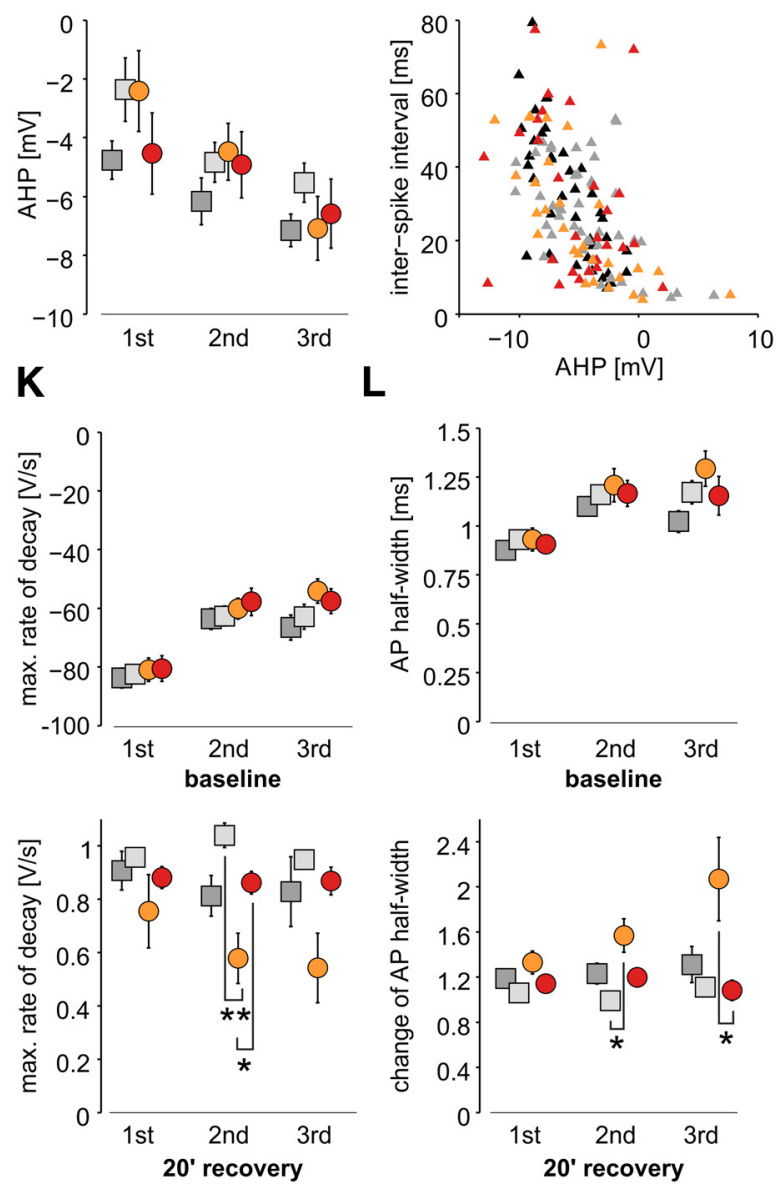

Figure 5. Altered firing properties of CA1 pyramidal neurons in APP ${ }^{-1-}$ and impaired AP generation after hypoxia, rescued by nifedipine and APPs $\alpha$-KI.A, Averaged AP shapes of CA1 pyramidal cells in WT, APPs $\alpha$-KI, APP ${ }^{-1-}$, and nifedipine-treated APP ${ }^{-1-}$ slices, shown as mean (darker line) \pm SEM (lighter shape) under baseline conditions and after recovery of hypoxia. The plots below each AP represent the averaged dV/dt trace. B, AP amplitude, defined as difference between the peak and the threshold (maximum of the second derivative) of an AP at baseline conditions (top); $p=0.000424$, one-way ANOVA, and its change after 20 min of recovery (bottom); $p=0.073$, one-way ANOVA. C, Maximal rate of rise, defined of the first derivative of an AP, at baseline (top); $p=$ 0.047, one-way ANOVA and its change after recovery (bottom); $p=0.01$, one-way ANOVA. $D$, Correlation between AP amplitude and rate of rise at baseline (top) and after recovery (bottom). Triangles represent a value pair from one cell in WT (black), APPs $\alpha$-KI (gray), APP ${ }^{-1-}$ (orange), and nifedipine-treated APP ${ }^{-1-}$ (crimson) tissue. Black line indicates least-squares linear regression. $r$, Pearson's linear correlation coefficient, $p, p$ value for Pearson's correlation using Student's distribution for transformation of correlation. $A-D,{ }^{*} p<0.05$ (one-way ANOVA with post hoc Tukey's Multiple Comparison Test). ${ }^{* *} p<0.01$ (one-way ANOVA with post hoc Tukey's Multiple Comparison Test). ${ }^{* * *} p<0.001$ (one-way ANOVA with (Figure legend continues.) 
show any difference toward WT cells with respect to AP waveform under baseline conditions or following hypoxia. There was a strong correlation between AP amplitude and rate of rise under baseline conditions as well as following hypoxia, without significant differences between groups (Fig. 5D).

To further investigate cellular excitability and the potency to maintain energy-demanding high-frequency firing rates, we elicited trains of APs by 500 ms current pulses during baseline conditions (Fig. 5E) and after recovery from hypoxia. The amplitude of the current pulse did not vary between the four groups and was between $0.51 \pm 0.10 \mathrm{nA}$ in $\mathrm{APP}^{-1-}$ and $0.64 \pm 0.11 \mathrm{nA}$ in APPs $\alpha$-KI cells ( $p=0.73$, one-way ANOVA). Each pulse evoked between $10.27 \pm 0.58 \mathrm{AP}$ in $\mathrm{APP} \alpha-\mathrm{KI}$ and $10.79 \pm 0.76 \mathrm{AP}$ in WT ( $p=0.94$, one-way, ANOVA). All cells showed spike frequency adaptation as typical for CA1 pyramidal cells without significant differences between groups. However, the first two ISIs showed a tendency to shorter times in $\mathrm{APP}^{-1-}$ cells compared with WT (Fig. 5F; $12.7 \pm 2.5 \mathrm{~ms}$ and $22.7 \pm 5.1 \mathrm{~ms}$ vs $16.4 \pm 2.6 \mathrm{~ms}$ and $38.8 \pm 5.0 \mathrm{~ms}$, respectively; $p=0.78$ and $p=$ 0.11 , respectively, one-way ANOVA). The AHP of the first two spikes appeared also smaller in APP ${ }^{-1-}$ compared with WT neurons without reaching significance (Fig. $5 G ;-2.37 \pm 1.09 \mathrm{mV}$ vs $-4.11 \pm 0.63 \mathrm{mV}, p=0.25$, one-way ANOVA). ISIs were strongly negatively correlated with AHP amplitude (Fig. $5 H ; \rho=$ $-0.48, p=1.15 \times 10^{-9}$ ).

During a train of AP, amplitude declined progressively, rates of rise and decay became slower and AP waveforms wider (Fig. $5 I-L)$. During baseline, the maximum rate of rise of the first three $\mathrm{AP}$ was smaller in $\mathrm{APP}^{-1-}$ compared with WT and to APPs $\alpha$-KI (Fig. 5J, top). In contrast, the rate of decay and the AP half-width did not differ significantly. Following recovery from hypoxia, kinetics of APs in APP ${ }^{-1-}$ mice was more severely altered than in the other groups. For example, rate of rise was significantly diminished in $\mathrm{APP}^{-1-}(56 \pm 10 \%$ of baseline value for the second $\mathrm{AP}$ vs $107 \pm 11 \%$ in nifedipine-treated $\mathrm{APP}^{-/-}$slices and $87 \pm$

(Figure legend continued.) post hoc Tukey's Multiple Comparison Test). Baseline: $n=15 / 14$ / 12/10 cells from 6/6/9/5 WT, APPs $\alpha$ - KI, APP ${ }^{-1-}$, and APP ${ }^{-1-}$ mice in presence nifedipine, respectively; recovery: $n=6 / 4 / 5 / 6$ cells from $4 / 4 / 4 / 4$ mice, respectively. $E$, Representative trains of AP in WT (left) and APP ${ }^{-1-}$ (right) cells elicited by a suprathreshold positive current injection of same magnitude during baseline recording. APs are truncated. $\boldsymbol{F}$, ISIs between the first four APs in a train in WT (dark gray), APPs $\alpha$ - KI (light gray), APP ${ }^{-1-}$ (orange), and and nifedipine-treated APP ${ }^{-1-}$ (crimson) tissue during baseline. G, AHP of the first three APs in an AP train during baseline. AHP amplitude was defined as the difference between the local minimum following an AP and its threshold. $\boldsymbol{H}$, Relationship between AHP and the ISI. Triangles represent a value pair from one cell. $I$, Superimposed representative trains of the first three APs in a train of a WT (left) and an APP ${ }^{-1-}$ cell (right) during baseline recording (top) and after recovery (bottom). Note the widening and the reduction of amplitude of the second and third AP of the APP ${ }^{-1-}$ cell after hypoxia. J, Maximum rate of rise of the first three APs in a train during baseline (top, $p=0.052, p=0.043, p=0.017$, respectively, one-way ANOVA) and its change after recovery (bottom, $p=0.004, p=0.0027, p=0.0026$, respectively, one-way ANOVA). $\boldsymbol{K}$, Maximum rate of decay, defined as minimum of the first derivative of an AP, of the first three APs in a train during baseline (top, $p=0.92, p=0.72, p=020$, respectively, one-way ANOVA) and its change after recovery (bottom, $p=0.47, p=0.008, p=0.1$, respectively, one-way ANOVA). $L$, Half-width of the first three APs in a train during baseline (top, $p=0.65, p=0.63, p=0.08$, respectively, one-way ANOVA) and its change after recovery (bottom, $p=0.18, p=0.023, p=0.018$, respectively, one-way ANOVA). $I-\boldsymbol{L},{ }^{*} p<$ 0.05 (one-way ANOVA with post hoc Tukey's Multiple Comparison Test). ${ }^{* *} p<0.01$ (one-way ANOVA with post hoc Tukey's Multiple Comparison Test). ${ }^{* * *} p<0.001$ (one-way ANOVA with post hoc Tukey's Multiple Comparison Test). Baseline: $n=14 / 15 / 11 / 9$ cells from 6/6/8/5 WT, APPs $\alpha$ - KI, APP ${ }^{-1-}$, and nifedipine-treated APP ${ }^{-1-}$ mice, respectively; recovery: $n=6 / 3 /$ $5 / 6$ cells from 4/3/4/4 WT, APPs $\alpha$ - KI, APP ${ }^{-/-}$, and nifedipine-treated APP ${ }^{-/-}$mice, respectively.
}

$8 \%$ in WT; Fig. $5 J$, bottom; $p=0.0027$, one-way ANOVA). The rate of decay slowed down to $58 \pm 9 \%$ of baseline $\left(\mathrm{APP}^{-1-}\right)$ versus $104 \pm 5 \%$ in APPs $\alpha$-KI (Fig. $5 K$, bottom; $p=0.008$, oneway ANOVA). AP width increased to $207 \pm 37 \%$ of baseline in the third AP of the train versus $108 \pm 9 \%$ in nifedipine-treated $\mathrm{APP}^{-1-}$ slices (Fig. $5 L$, bottom; $p=0.018$, one-way ANOVA).

\section{Compromised recovery of spontaneous network activity in APP $^{-1-}$}

Mouse hippocampal slices exhibit spontaneous sharp waveripple (SPW-R) activity, characterized by propagating field potential waves with superimposed fast oscillations at $\sim 200 \mathrm{~Hz}$ and time-locked APs (Fig. 6A-C) (Maier et al., 2003; Both et al., 2008). Network oscillations are highly energy demanding processes (Kann, 2011) that are vital for information processing in the brain (Buzsáki and Draguhn, 2004) and are impaired in AD patients and mouse models of AD (Sanchez et al., 2011; Verret et al., 2012). Therefore, we analyzed hippocampal SPW-R activity in slices from WT, $\mathrm{APP}^{-1-}$, and $\mathrm{APP} s \alpha$-KI mice. Under basal conditions, frequency of SPW-R in CA1 and CA3 was similar in all groups (Fig. 6D). Likewise, further features, such as SPW-R amplitude as well as the frequency and energy content of superimposed ripple oscillations, were unaltered (data not shown). After 2-3 min of hypoxia, network oscillations were abolished in all slices (Fig. 6A, $B, E$ ). Recovery after reoxygenation, however, was strongly different between genotypes and brain regions: in $\mathrm{CA} 3$, slices from $\mathrm{APP}^{-1-}$ mice showed delayed and incomplete recovery of SPW-R frequency (Fig. 6E,F) and reduced ripple energy (Fig. 6G) compared with WT. Network activity in CA1 recovered incompletely within the time of observation, reaching $\sim 60 \%-70 \%$ of the initial frequency of SPW-R. However, in this hippocampal subfield, time course and degree of recovery were similar for all three genotypes (Fig. $6 E-G$ ). Interestingly, waveforms and propagation of SPW-R were largely normal after recovery from hypoxia in all genotypes, indicating intact mechanisms of neuronal interactions in local networks (Fig. 6C). Nifedipine $(10 \mu \mathrm{M})$ did not alter properties of spontaneous network activity (data not shown). However, the drug restituted recovery from hypoxia in slices from $\mathrm{APP}^{-/-}$mice (Fig. $6 F, G$ ), in line with our results on evoked population spikes.

\section{Increased incidence of hypoxia-induced spreading depression in APP $-1-$}

Consistent with previous findings (Aitken et al., 1998; Somjen, 2001; Foster et al., 2005), hypoxia induced spreading depressions in a subset of slices, characterized by long-lasting negative field potential transients of $10-30 \mathrm{mV}$ and accompanying membrane potential depolarization in pyramidal cells (Fig. 7A). Slices from $\mathrm{APP}^{-1-}$ mice were significantly more likely to develop HSD during the 5 min hypoxic period than WT slices ( 16 of 22 slices from $\mathrm{APP}^{-1-}$ mice and 3 of 18 slices from WT animals; $p<0.001$; Tukey's multiple comparison of proportions) (Fig. $7 B$ ). Nifedipine $(10 \mu \mathrm{M})$ reduced the probability of HSD in $\mathrm{APP}^{-1-}$ slices to the level of WT tissue (HSD in 3/14 vs 3/11 slices, respectively; Fig. $7 C)$, whereas APV $(60 \mu \mathrm{M})$ did not prevent HSD generation in $\mathrm{APP}^{-1-}$ (SD in 9/13 vs $1 / 14$ slices, respectively; $p<0.001$ ). Propensity for SD appeared also higher in slices from APPs $\alpha$-KI, although there was no significant difference toward WT (Fig. 7B). Notably, we found a correlation between SPW-R frequency under baseline conditions and the probability of HSD (Fig. 7D). The risk to develop a spreading depression was significantly higher in slices with high $(>3 \mathrm{~Hz})$ incidence of SPW-R than in those with lower frequency of network events (1-2 Hz; both CA1 and CA3). 

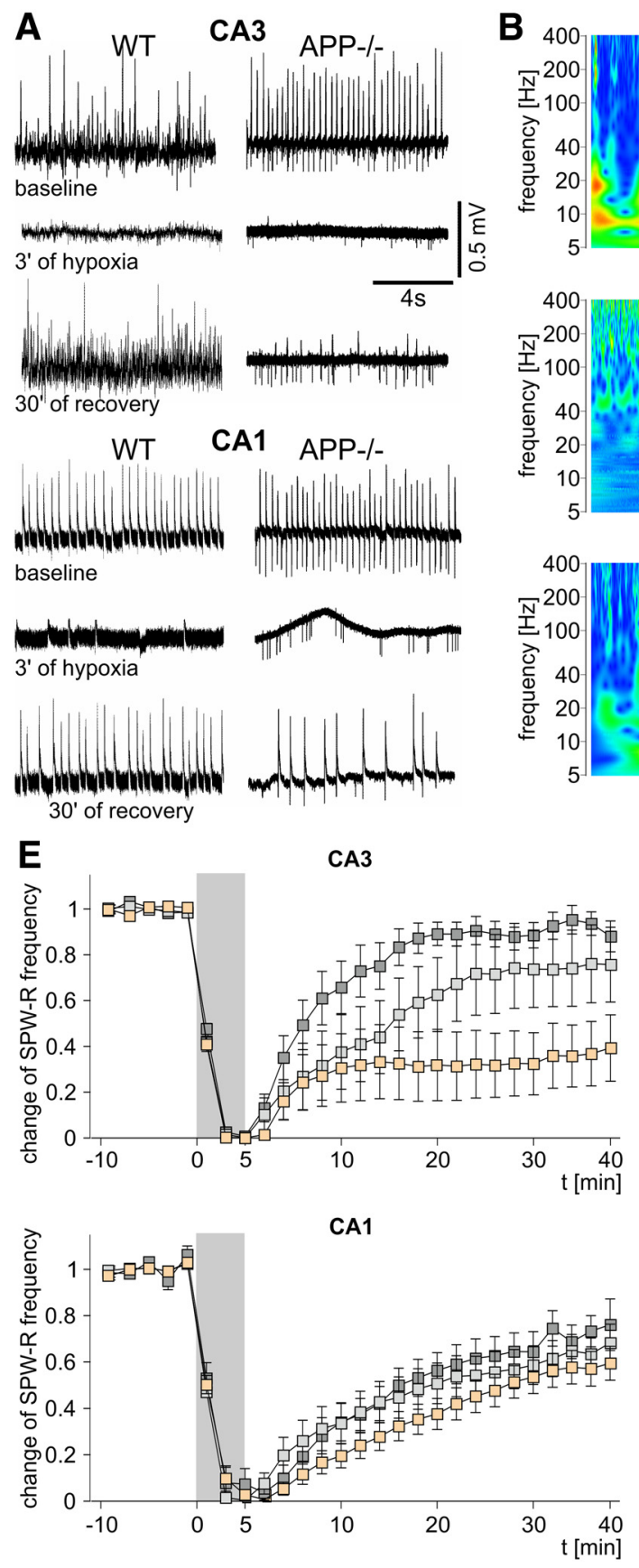

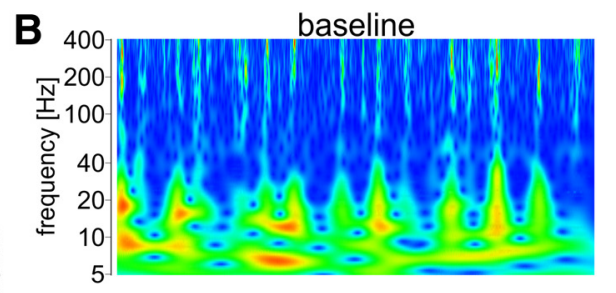

5 ' of hypoxia

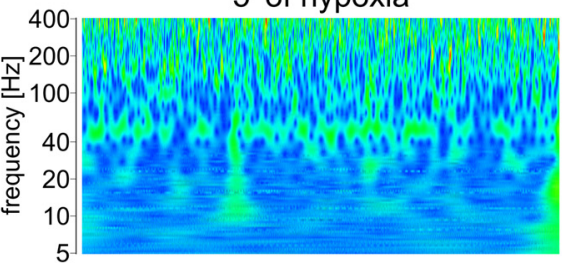

30 ' of recovery
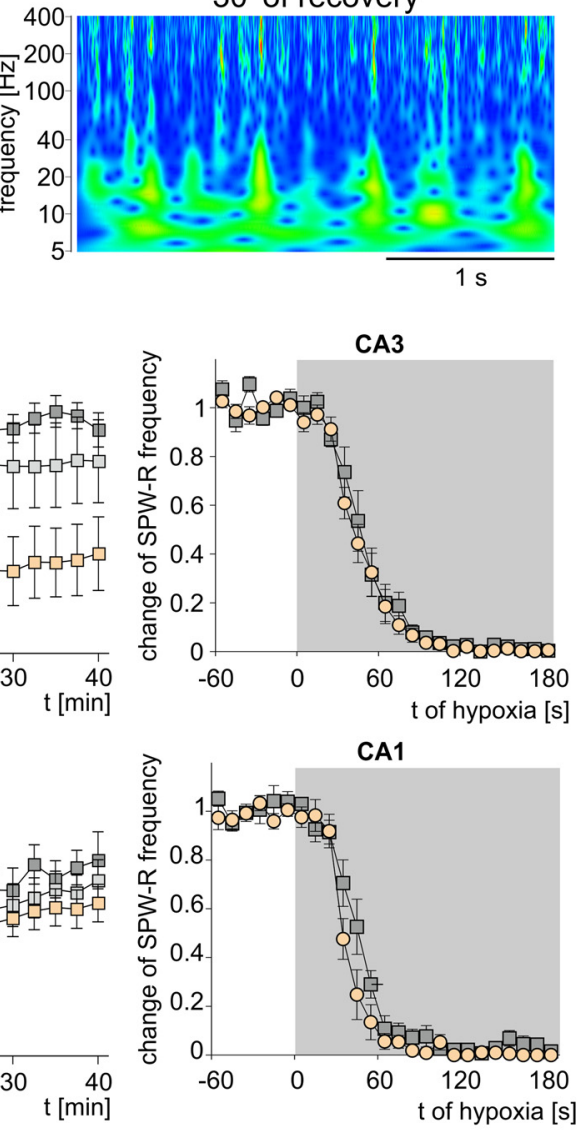

C

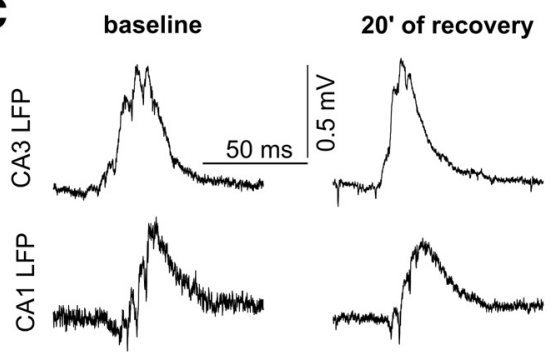

D

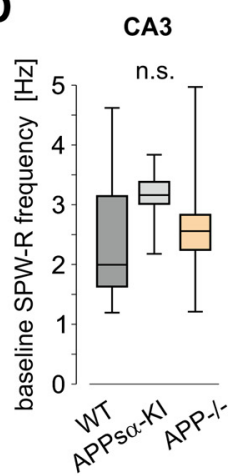

CA1

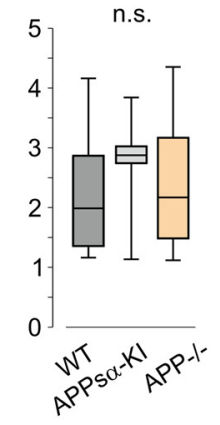

$\mathbf{F}$
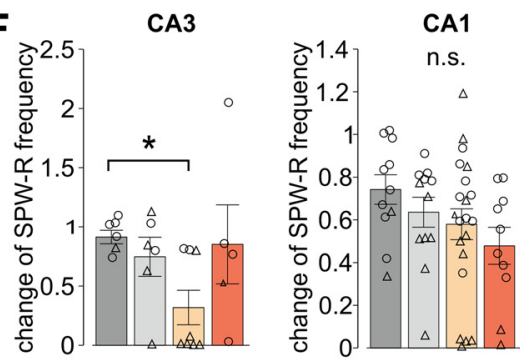

G

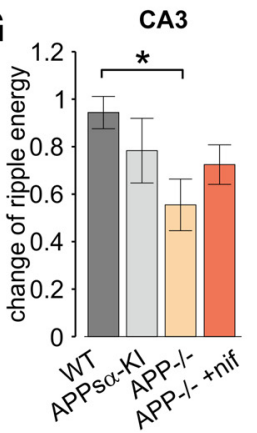

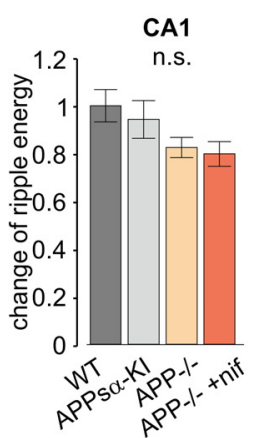

Figure 6. Impaired recovery of spontaneous sharp wave-ripple activity in CA3, but not CA1 in APP ${ }^{-1-}$. A, Representative LFP recordings of spontaneous SPW-R activity in WT and APP ${ }^{-1-}$ slices in CA3 and CA1 during baseline, at 3 min of hypoxia, and after 30 min of recovery. B, Power spectra in the CA3 region of an APP ${ }^{-1-}$ slice under baseline conditions, after 5 min of hypoxia, and after 30 min of recovery. C, Example of SPW-R propagation from CA3 to CA1 in an APP ${ }^{-1-}$ slice during baseline and after recovery from hypoxia. $D$, Baseline SPW-R frequency in CA3 (left, $n=18 / 6 / 17$ slices from 10/3/14 WT, APPs $\alpha$-Kl and APP ${ }^{-1-}$ mice, respectively; $p=0.35$, one-way ANOVA) and CA1 (right, $n=22 / 12 / 34$ slices from 12/4/15 WT, APPs $\alpha$-Kl and APP ${ }^{-1-}$ mice, respectively; $p=0.21$, one-way ANOVA). $\boldsymbol{E}$, Time courses of SPW-R frequency in slices from the three genotypes in CA3 (top) and CA1 (bottom). Subplots on the right zoom in on the first 3 min of hypoxia. $\boldsymbol{F}$, Change of SPW-R frequency after $30-40$ min of recovery from hypoxia in CA3 ( $n=7 / 6 / 8$ slices from $5 / 3 / 6$ WT, APPs $\alpha-K I$, and APP ${ }^{-1-}$ mice, respectively; $p=0.025$, one-way ANOVA) and CA 1 $(n=9 / 12 / 20$ slices from $5 / 4 / 8$ mice; $p=0.71$, one-way ANOVA). Circles represent single experiments without HSD. Triangles represent experiments with occurrence of an HSD. G, Change of ripple energy after recovery in CA3 ( $p=0.043$, one-way ANOVA) and CA1 ( $p=0.10$, one-way ANOVA). ${ }^{*} p<0.05$ (one-way ANOVA with post hoc Tukey's Multiple Comparison Test). ${ }^{* *} p<0.01$ (one-way ANOVA with post hoc Tukey's Multiple Comparison Test). n.s., Not significant.

Other parameters, such as PS amplitude, fEPSP slope, and PPR, did not correlate with risk of HSD. Importantly, the reduced recovery of PS amplitude was also present in those $\mathrm{APP}^{-1-}$ slices, which had not undergone HSD (Fig. 7E, left), excluding that the hypoxia-induced functional deficits described are secondary to spreading depression. On the other hand, PS in APPs $\alpha$-KI slices, which had undergone an HSD, tended to recover better than in $\mathrm{APP}^{-1-}$ slices with HSD (Fig. 7E, right). HSD occurred after $211 \pm 15 \mathrm{~s}$ in $\mathrm{APP} \alpha-\mathrm{KI}$ and $212 \pm 18 \mathrm{~s}$ in $\mathrm{APP}^{-1-}$ slices. We found no correlation between the latency to the onset of HSD and recovery of PS amplitude (Fig. 7F). In most slices, electrophysiological parameters showed at least partial recovery following SD. 
A
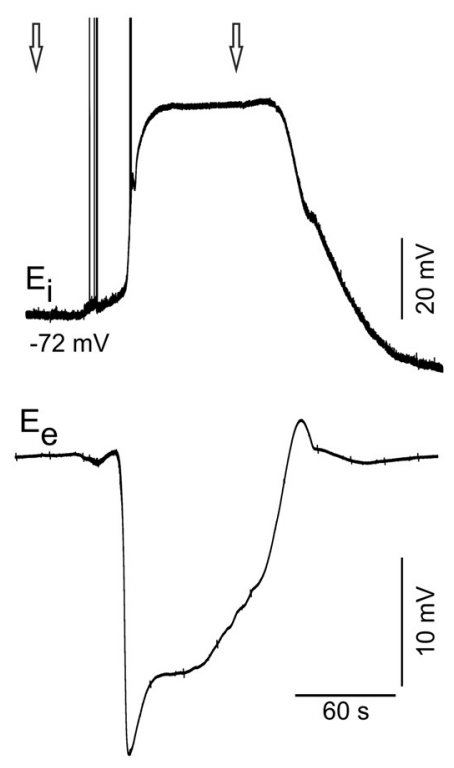

B

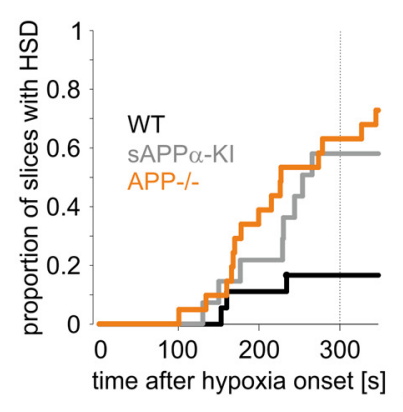

D

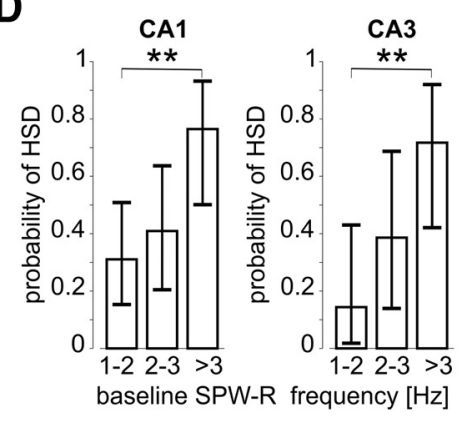

C

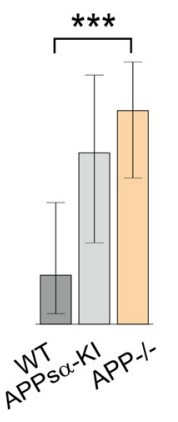

E

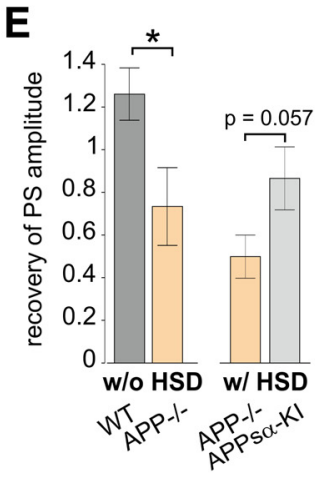

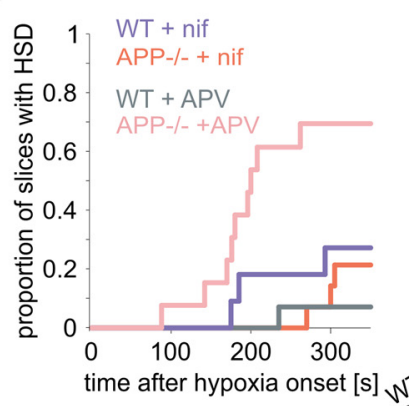

$\mathbf{F}$

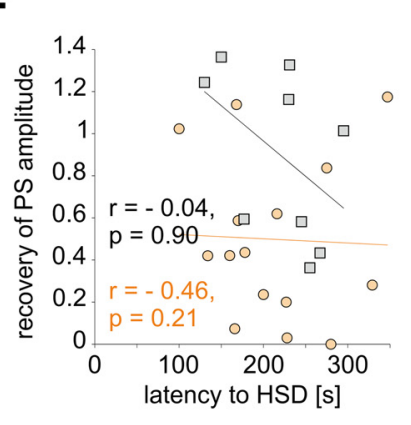

Figure 7. Increased risk of hypoxia-induced spreading depression in APP ${ }^{-1-}$ slices lowered to WT level by nifedipine. $A$, Example of a hypoxia-induced spreading depression in an APP ${ }^{-1-}$ slice. Left arrow indicates $180 \mathrm{~s}$ after hypoxia induction. Right arrow indicates end of hypoxia. Top, Intracellular recording from a CA1 pyramidal cell with a sharp electrode. Bottom, LFP recording in CA1, stratum pyramidale. $\boldsymbol{B}$, Probability of HSD. An HSD occurred in $3 / 18$ of WT, $7 / 12$ of APPs $\alpha-\mathrm{KL}$, and 16/22 of APP ${ }^{-1-}$ slices. $p<0.001$ (Tukey's multiple comparison of proportions). C, Probability of HSD in WT and APP ${ }^{-1-}$ slices treated with nifedipine (HSD in $3 / 11$ and $3 / 14$ slices, respectively; $p=0.73, \chi^{2}$ test for comparison of two proportions) and APV (HSD in $1 / 14$ and $9 / 13$ slices, respectively; ${ }^{* * *} p=0.00084, \chi^{2}$ test for comparison of two proportions). $\boldsymbol{D}$, Probability of HSD in correlation to the baseline SPW-R frequency in CA1 and CA3. ${ }^{* *} p<0.01$ (Tukey's multiple comparison of proportions). $\boldsymbol{B}-\boldsymbol{D}$, Error bars indicate Clopper-Pearson Cls for $\alpha=0.05$. $E$, Left, Recovery of PS in WT and APP ${ }^{-/-}$slices without occurrence of an HSD (12/6 slices from 7/3 mice, respectively). ${ }^{*} p=0.042$ (two-sided Mann-Whitney UTest). n.s., Not significant. Right, Recovery of PS in APP ${ }^{-1-}$ and APPs $\alpha$-KI slices with HSD ( $16 / 7$ slices from 7/3 mice, respectively, $p=0.057$, two-sided Mann-Whitney U Test). $\boldsymbol{F}$, Correlation between latency to HSD and recovery of PS amplitude in WT (gray squares, black regression line) and APP ${ }^{-1-}$ (orange circle and regression line) slices.

However, some slices from $\mathrm{APP}^{-1-}$ mice did not regain normal population spikes (Fig. 1E) and network activity (Fig. $6 F$ ).

\section{Enhanced calcium influx in APP ${ }^{-/-}$slices during hypoxia}

Our previous results indicate that the increased sensitivity of APP-deficient hippocampal neurons to hypoxia strongly depends on activity of L-type calcium channels. We therefore performed calcium imaging experiments in parallel to LFP recording in CA1 to compare the calcium dynamics under hypoxia between slices from APP ${ }^{-1-}$ and WT mice (Fig. 8A). Neurons were bulkloaded with OGB-1, and hypoxia was maintained until the onset of spreading depression. Hypoxia induced a slow increase in the calcium signal (Fig. $8 E-H$ ), followed by a rapid fluorescence peak, corresponding to an SD (Fig. $8 I-L$ ). Typically, the calcium elevation reached a plateau potential before SD. The amplitude of this signal was increased in APP ${ }^{-1-}$ mice, and time to onset of SD was reduced (Fig. $8 B, F, J)(n=7 / 9$ slices from $4 / 5 \mathrm{WT}$ and $\mathrm{APP}^{-1-}$ mice, respectively; $p=0.031, p=0.042$, respectively, two-sided Mann-Whitney $U$ Test). Both effects were rescued in the presence of nifedipine $(10 \mu \mathrm{M})$ (Fig. $8 C, G, K)$. In an additional, independent set of experiments, we compared WT and APPs $\alpha$-KI slices (Fig. 8D,H,L) and found no differences in the change of calcium signal intensity $(p=0.86)$ and time to peak intensity $(p=0.46)$ between these groups $(6 / 9$ slices from $2 / 3$ mice, respectively).

\section{Deficits in $\mathrm{APP}^{-1-}$ are not attributed to acute cell death}

To test for induction of apoptosis, we stained hippocampal slices with the nuclear dye DAPI as well as antibodies against the neu- ronal marker NeuN (Mullen et al., 1992) and the early apoptosis marker annexin V (Bahmani et al., 2011). Tissue was fixed directly after preparation, at $40 \mathrm{~min}$ after hypoxia, and at $4 \mathrm{~h}$ after hypoxia. As a control, 2-3 slices per genotype were kept in nonhypoxic conditions and fixed after 3-4 h (the usual incubation time) and after $9 \mathrm{~h}$ (the maximal total duration of experiments). Numbers of $\mathrm{NeuN}^{+}$and annexin $\mathrm{V}^{+}$cells were used to calculate a "vitality score." $\mathrm{NeuN}^{+}$/annexin ${ }^{-}$cells scored $1, \mathrm{NeuN}^{+} /$ annexin $^{+}$and unstained cells scored 0.5 , and $\mathrm{NeuN}^{-}$/annexin ${ }^{+}$ cells scored 0 points. In slices of all genotypes, which were fixed directly after incubation annexin $\mathrm{V}$-staining, was largely absent in CA1 (Fig. 9Aa). Likewise, slices fixed after 3-4 or $9 \mathrm{~h}$ of incubation in normoxic conditions showed largely unaltered $\mathrm{NeuN}$ and annexin V fluorescence (Fig. 9Ab) and no significant reduction in vitality. Following hypoxia, some cell nuclei adopted a typical pyknotic form and were surrounded by an annexin-stained matrix and by fragments of NeuN-stained material, in contrast to the homogeneous staining in unaffected neurons (Fig. 9Ac,Ad). The percentage of annexin ${ }^{+}$cells increased, whereas numbers for NeuN staining decreased (Fig. 9B). The vitality of slices after hypoxia was highly variable, and we found no significant differences between genotypes or between slices fixed at $40 \mathrm{~min}$ or at $4 \mathrm{~h}$ after hypoxia (Fig. 9C). However, WT and $\mathrm{APP}^{-1-}$ slices fixed $40 \mathrm{~min}$ after hypoxia as well as $\mathrm{APP}^{-1-}$ slices fixed $4 \mathrm{~h}$ after hypoxia had a significantly reduced score compared with baseline, whereas vitality scores in APPs $\alpha$-KI and nifedipine-treated $\mathrm{APP}^{-/-}$slices were not significantly altered (Fig. 9C). This finding underlines the protective effect of $\operatorname{APPs} \alpha$ - and nifedipine 

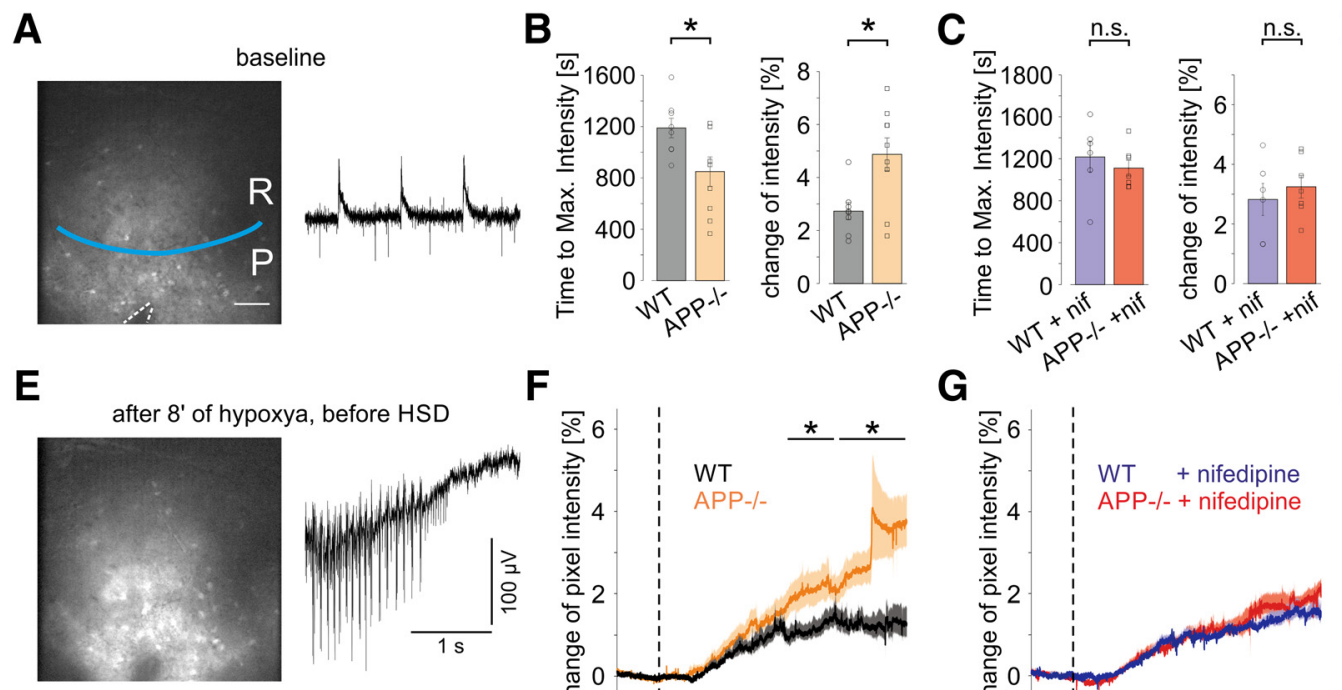

$\mathbf{F}$
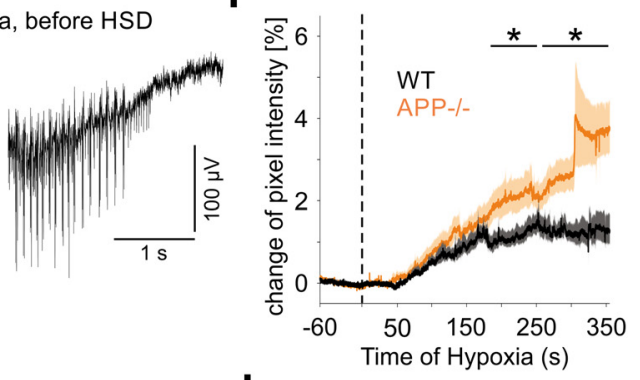

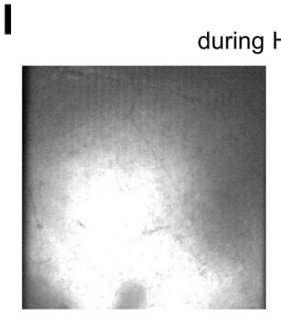

calcium signal

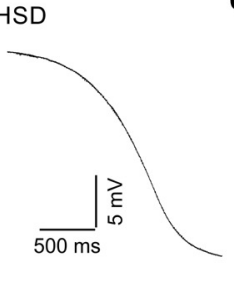

LFP recording
$\mathbf{J}$

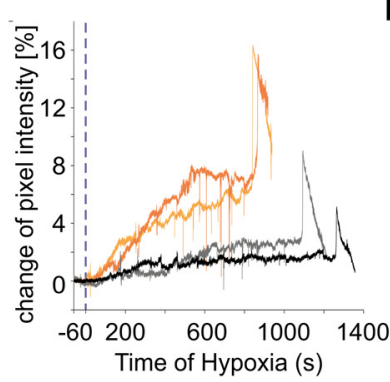

G

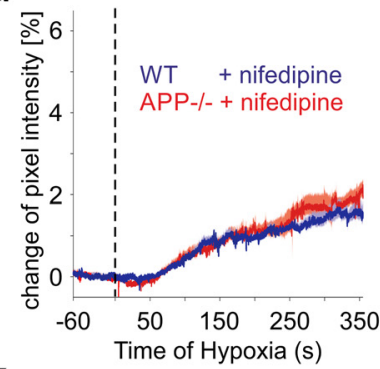

K

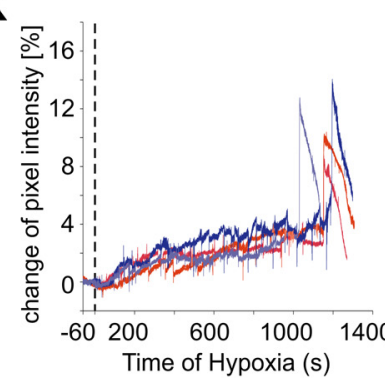

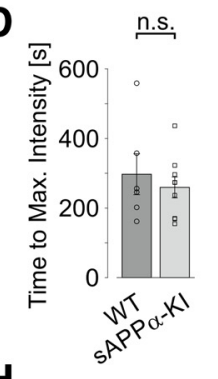

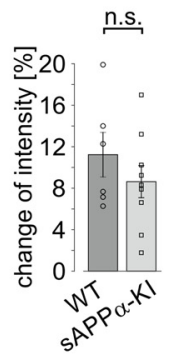

H
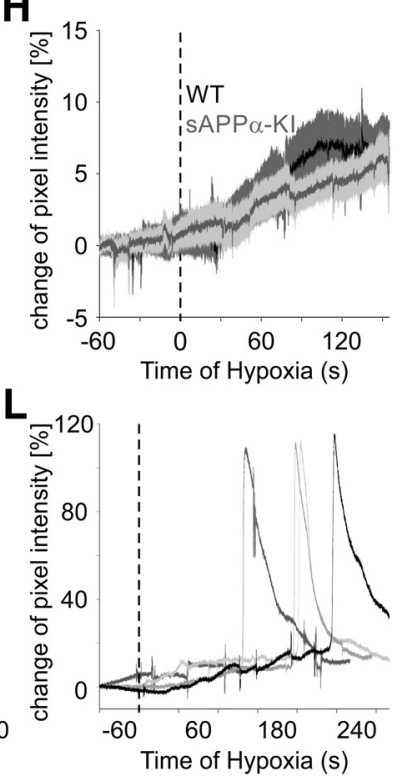

Figure 8. Increased calcium influx through LTCC reduces latency to HSD in APP ${ }^{-/-}$. $\boldsymbol{A}, \boldsymbol{E}, \boldsymbol{I}$, Examples of calcium imaging in CA1 (left) and the corresponding LFP recording from CA1p during baseline conditions $(\boldsymbol{A})$, the plateau-like phase before the spreading depression $(\boldsymbol{E})$, and HSD $(\boldsymbol{I})$. $\boldsymbol{A}, \mathrm{P}, \mathrm{CA1p}$; R, CA1r. Blue line indicates approximate border between $C$ A1p and CA1r. Dashed lines (bottom) indicate the position of the pipette. White bar represents $50 \mu \mathrm{m}$. $\boldsymbol{B}$, Latency to the peak of fluorescence intensity (left, ${ }^{*} p=0.0311$, two-sided Mann-Whitney $U$ Test) and increase of fluorescence intensity at the plateau before HSD (right, ${ }^{*} p=0.0418$, two-sided Mann-Whitney U Test) in untreated WT and APP ${ }^{-1-}$ slices ( $n=7 / 9$ slices from $4 / 5$ mice, respectively). n.s., Not significant. C, Latency to the peak of fluorescence intensity (left, 0.7984, two-sided Mann-Whitney U Test) and increase of fluorescence intensity at the plateau before HSD (right, 0.2925 , two-sided Mann-Whitney U Test) in nifedipine-treated WT and APP ${ }^{-1-}$ slices (6/7 slices from 2/3 mice, respectively). $D$, Latency to the peak of fluorescence intensity (left, $p=0.86$, two-sided Mann-Whitney U Test) and increase of fluorescence intensity at the plateau before HSD (right, $p=0.46$, two-sided Mann-Whitney U Test) in untreated WT and sAPP $\alpha$-KI slices (6/9 slices from 2/3 mice, respectively). $\boldsymbol{F}$ - $\boldsymbol{H}$, Mean increase of fluorescence intensity in untreated $(\boldsymbol{F})$, nifedipine-treated $(\boldsymbol{G})$, WT and APP ${ }^{-/-}$and untreated WT and sAPP $\alpha$-KI slices $(\boldsymbol{H})$ during hypoxia. The dotted line indicates the start of hypoxia. $J-\boldsymbol{L}$, Increase of fluorescence intensity in each two representative untreated $(\boldsymbol{J})$, nifedipine-treated $(\boldsymbol{K})$ WT and APP ${ }^{-/-}$and untreated WT and sAPP $\alpha$-KI slices ( $\left.\boldsymbol{L}\right)$ during hypoxia.

against hypoxia-induced cell damage. Interestingly, the nuclear area was reduced in most slices after 3-4 h of incubation (data not shown) or after hypoxia compared with baseline (not different between genotypes), but not after $9 \mathrm{~h}$ of incubation in normal oxygen conditions (Fig. 9D). Nuclear areas were positively correlated with vitality scores (Fig. 9E) with most $\mathrm{NeuN}^{+} /$annexin $^{-}$ cells with a cross-sectional area between 50 and $100 \mu \mathrm{m}^{2}$ and the majority of $\mathrm{NeuN}^{-}$/annexin ${ }^{+}$cells with an area of $\sim 30 \mu \mathrm{m}^{2}$.

Fast-spiking parvalbumin-positive $\left(\mathrm{PV}^{+}\right)$interneurons contribute essentially to temporally coordinated hippocampal network activity. Because APP has been reported to affect GABAergic inhibition via modulation of LTCC (Yang et al., 2009), we evaluated cell death in $\mathrm{PV}^{+}$interneurons (Fig. $9 F-H$ ). PV immunostaining revealed cells with highly branched arborization within the CAlp layer and varicose dendrites reaching far into CA1r, without apparent differences in cell count and morphology between groups (Fig. 9F). The amount of $\mathrm{PV}^{+}$cells stained positively for annexin (Fig. $9 G$ ) did not vary significantly between groups and conditions (Fig. 9H). Together, these data show that within our time of observation hypoxia does induce a certain amount of cell death. The functional deficits observed in $\mathrm{APP}^{-1-}$ slices, however, are not due to increased neuronal loss following transient hypoxia.

\section{Discussion}

The normal functions of APP and its cleavage products remain largely unknown, despite the importance of these molecules in $\mathrm{AD}$ (O'Brien and Wong, 2011). Here, we show that APP has an acute neuroprotective function following transient hypoxia in hippocampal tissue. Functional recovery was strongly enhanced by APP via control of calcium load through LTCCs. Our findings are in line with earlier studies suggesting a neuroprotective role of APP in vitro (Kögel et al., 2012) and in vivo (Clarke et al., 2007; Koike et al., 2012). The effects seem to be mostly mediated by the soluble extracellular domain APPs $\alpha$, which was sufficient to rescue most cellular and network functions. Interestingly, earlier studies focusing on neuronal damage have suggested a similar protective role of APPs $\alpha$ (SmithSwintosky et al., 1994; Thornton et al., 2006).

\section{Normal network function of APP ${ }^{-/-}$tissue under baseline conditions}

In our present and previous (Zhang et al., 2013) studies, baseline synaptic and network functions were largely unaltered in $\mathrm{APP}^{-1-}$ mice, probably due to compensatory activities of the homologous proteins APLP1 and APLP2 (Weyer et al., 2011; Hick et al., 2015). At the cellular level, however, APP ${ }^{-1-}$ neurons showed functional alterations, such as depolarized resting mem- 
A
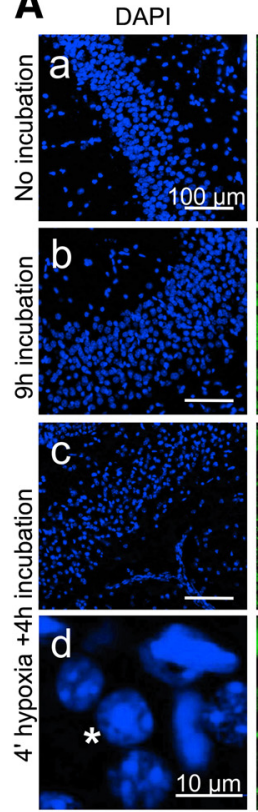

F
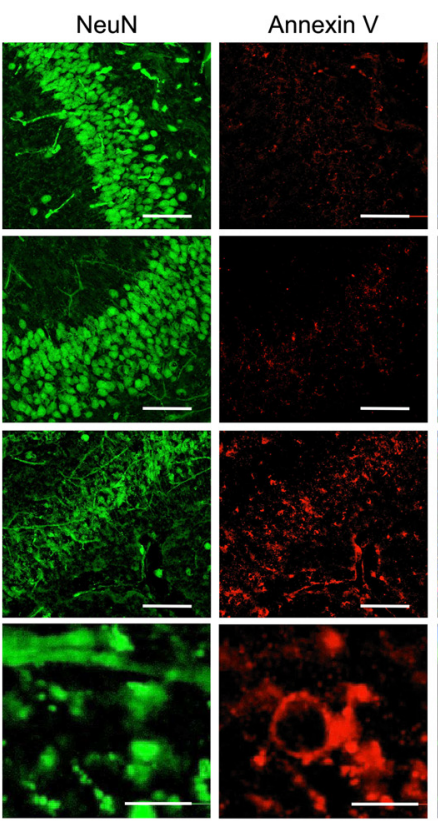

4

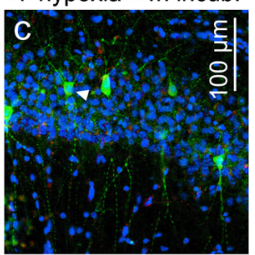

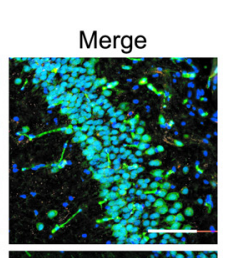
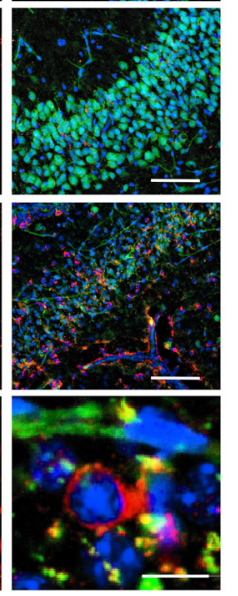

G
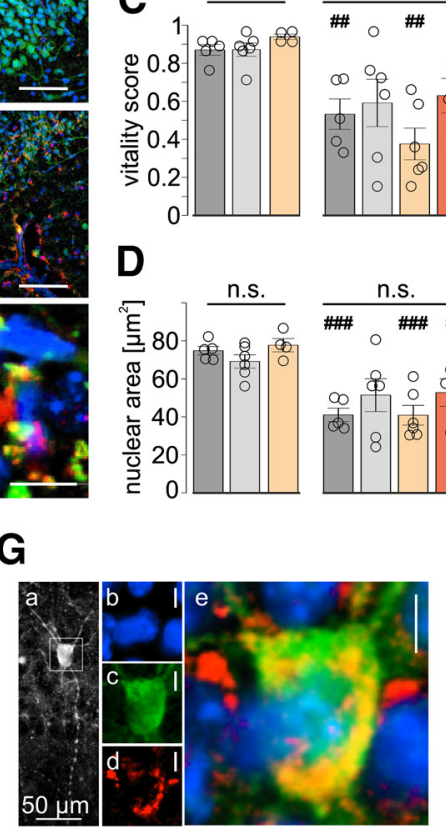
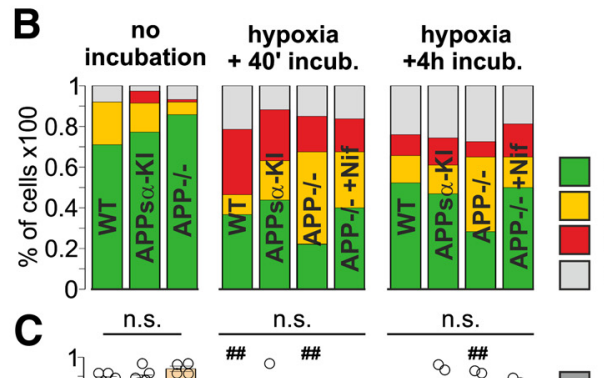

NeuN+/Annex-

NeuN+/Annex+

NeuN- /Annex+

NeuN- /Annex-

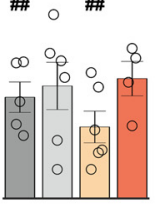

n.s.
$8 \stackrel{\infty}{\#}+\infty$
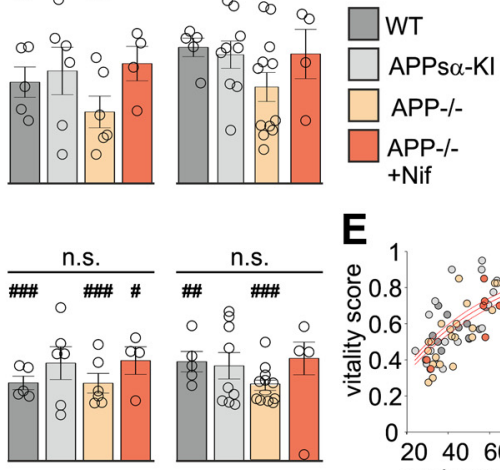

E

H
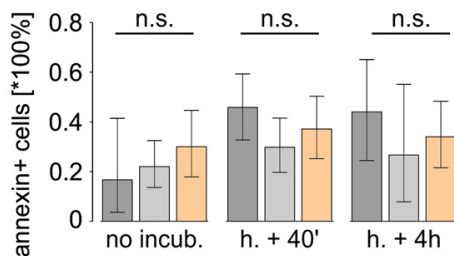

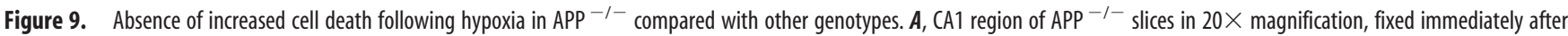
preparation $(\boldsymbol{A} \boldsymbol{a})$, after $9 \mathrm{~h}$ of incubation $(\boldsymbol{A} \boldsymbol{b})$, and after the hypoxia experiment plus additional $4 \mathrm{~h}$ incubation $(\boldsymbol{A c})$. $\boldsymbol{A d}$, Zoom on a pyknotic nucleus from $\boldsymbol{A c}$, labeled with an asterisk. $\boldsymbol{B}$, NeuN and annexin V staining behavior in slices fixed directly after cutting ( $n=5 / 6 / 4 \mathrm{WT}, \mathrm{APP} s \alpha-\mathrm{Kl}$, and APP ${ }^{-1-}$ slices, respectively), directly after the hypoxia experiment (including 40 min of recovery, $n=$ 5/6/6/4 WT, APPs $\alpha$-KI, APP ${ }^{-/-}$, and nifedipine-treated APP $-/-$slices, respectively) or after hypoxia plus four additional hours of incubation ( $n=5 / 9 / 12 / 4$ WT, APPs $\alpha$-KI, APP $-/-$, and nifedipine-treated APP ${ }^{-1-}$ slices, respectively). Only cells showing somatic NeuN staining were considered NeuN ${ }^{+}$. Green represents NeuN ${ }^{+}$and annexin ${ }^{-}$(putatively healthy) cells. Yellow represents both $\mathrm{NeuN}^{-}$and annexin ${ }^{+}$(possibly ongoing apoptosis) cells. Red represents NeuN ${ }^{-}$and annexin ${ }^{+}$(putatively dead) cells. Gray represents unstained cells. C, Vitality score of slices: $0=$ maximum death; $1=$ maximum vitality. Twenty cells per section and $4-8$ sections per slice $(n=1)$ were analyzed. NeuN ${ }^{+} /$annexin $^{-}$cells scored 1 , NeuN ${ }^{+} /$annexin $^{+}$and unstained cells scored 0.5 , and $\mathrm{NeuN}^{-}$/annexin ${ }^{+}$cells scored 0 points. $\boldsymbol{D}$, Nuclear cross-sectional area. There were no significant difference between genotypes in the three conditions (one-way ANOVA). ${ }^{\#} p<$ 0.05 , difference within genotype compared with slices fixed directly after cutting (Mann-Whitney UTest). \#\# $p<0.01$, difference within genotype compared with slices fixed directly after cutting

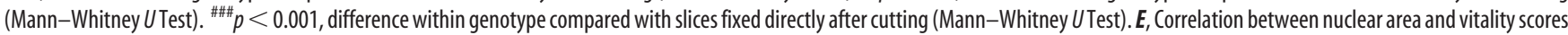
in all sections combined. The color of the dots corresponds to the genotype. Red lines indicate a fit to the exponential function $\left(f(x)=1-e^{(-b \times x)}, b=0.02101\right)$ and its $95 \%$ confidence limits $(b=[0.01942,0.0226]) . F$, Merged fluorescent images of the (A1 region of triple APP ${ }^{-1-}$ slices stained against parvalbumin (green), annexin V (red), and with DAPI (blue) immediately after dissection $(\boldsymbol{F a})$, after $9 \mathrm{~h}$ of incubation $(\boldsymbol{F b})$, and after hypoxia with four additional hours of incubation $(\boldsymbol{F} \boldsymbol{c})$. White bars represent $100 \mu \mathrm{m}$. $\mathbf{G}, \mathbf{M a g n i f i e d}$ images of a parvalbumin ${ }^{+}$and annexin ${ }^{+}$ neuron marked with a white arrowhead $(\boldsymbol{F} \mathbf{c})$. Ga, Anti-parvalbumin staining. Rectangle represents the field of view in $\mathbf{G} \boldsymbol{b}-\mathbf{G e}$. $\mathbf{G} \boldsymbol{b}-\mathbf{G e}, \mathbf{M a g n i f i e d}$ image of the soma stained with DAPI (Gb), anti-parvalbumin $(\mathbf{G c})$, anti-annexin V $(\mathbf{G d})$, and the merged image $(\mathbf{G e})$. White bars represent $5 \mu \mathrm{m}$. $\boldsymbol{H}$, Proportion of annexin ${ }^{+}$parvalbumin ${ }^{+}$neurons in WT, APPsa-KI, and APP ${ }^{-\prime-}$ slices immediately after dissection (3/18, 18/82, and 15/50 annexin ${ }^{+}$cells, respectively), after the hypoxia experiment (27/59, 22/74, and 23/62 annexin ${ }^{+}$cells, respectively), and after hypoxia plus four additional hours of incubation (11/25, 4/15, and 18/53 annexin ${ }^{+}$cells, respectively). Error bars indicate Clopper-Pearson Cls for proportions for $\alpha=0.05$. The number of slices corresponds to the number of slices in $\boldsymbol{B}-\boldsymbol{E}$. n.S., Not significant. $p=0.43, p=0.16, p=0.51$ for the three conditions (Tukey's multiple comparison of proportions). n.S., Not significant.

brane potential and reduced AP amplitude. They were also absent in nifedipine-treated $\mathrm{APP}^{-/-}$slices and in tissue from $\mathrm{APP} s \alpha-\mathrm{KI}$ mice, indicating a direct or indirect interaction between APPs $\alpha$ and LTCC. The slight decrease in AP amplitude may well be secondary to the partial inactivation of sodium channels under resting conditions (Cantrell and Catterall, 2001). Despite unaltered network function in normal oxygen, the depolarized membrane potential may well contribute to increased calcium influx and subsequent functional deficits under challenging conditions, such as hypoxia.

Facilitated cellular response to hypoxia and HSD occurrence in $\mathrm{APP}^{-1-}$ neurons

Under hypoxia, $\mathrm{APP}^{-1-}$ neurons showed faster increase of calcium levels and enhanced initial hyperpolarization. These differ- ences point toward altered regulation of calcium influx (see below) and hypoxia-induced outward potassium currents (Martin et al., 1994; Misonou et al., 2005). Notably, outward K ${ }^{+}$ current may mediate some forms of neuronal apoptosis (Yu et al., 1997). At the network level, the incidence of hypoxic spreading depression was strongly increased in $\mathrm{APP}^{-1-}$ slices. This widespread breakdown of membrane potential and ion gradients can be observed under conditions of severe neuronal stress, such as subarachnoid hemorrhage (Dreier et al., 2009) and ischemia (Dohmen et al., 2008), underlining the increased vulnerability of $\mathrm{APP}^{-1-}$ tissue. Interestingly, incidence of HSD correlated with baseline network (SPW-R) activity. These events go along with increased neuronal firing rates (Csicsvari et al., 1999) and may thus enhance metabolic demands (Kann, 2011) and vulnera- 
bility to HSD. Importantly, however, the deficient recovery from hypoxia in $\mathrm{APP}^{-1-}$ mice was also present in slices without HSD and thus constitutes and independent pathophysiological mechanisms.

\section{Impaired population spike generation and high-frequency firing in APP ${ }^{-1-}$ following hypoxia}

Despite largely unaltered fEPSP recovery from a transient hypoxic episode, spike generation in CA1 recovered much slower and less completely in $\mathrm{APP}^{-1-}$ slices. This indicates impaired excitation-spike coupling in CA1 following hypoxia. At the cellular level, we found decreased amplitude and rate of rise of APs following hypoxia. These and further small differences in (repetitive) AP firing appear too subtle, however, to explain the lasting posthypoxic reduction in population spike amplitude by $>40 \%$. Indeed, with stronger stimulation, we could evoke maximal population spike amplitudes much closer to control tissue, again pointing to altered excitation-spike coupling, rather than intrinsic excitability itself. In any case, generation of repetitive spikes and lasting synaptic activity require effective restoration of sodium and potassium gradients and are thus highly energy-demanding (Liotta et al., 2012). Thus, the functional deficits in $\mathrm{APP}^{-1-}$ slices may indicate disturbed energy and ion homeostasis after hypoxia.

\section{Impaired generation of spontaneous network activity following hypoxia}

SPW-R activity was rapidly abolished during hypoxia, but recovered partially in most slices, even following a spreading depression. After reoccurrence of the spontaneous network activity, the intrinsic features of SPW-R, such as ripple frequency, phasecoupled unit firing, and propagation from CA 3 to CA1, remained remarkably stable. Some APP ${ }^{-1-}$ slices, however, were not able to regain spontaneous SPW-R activity, and average SPW-R frequency as well as ripple energy remained significantly reduced compared with WT. Coordinated network oscillations require highly precise balance between inhibition and excitation (Maier et al., 2003; Nimmrich et al., 2005), intact function of interneurons (Klausberger et al., 2003), and highly efficient energy supply (Kann et al., 2014). The deficient recovery of network activity following hypoxia is thus in line with a role of APP in metabolic stress resistance.

\section{Reduction of hypoxia-induced calcium influx via LTCC as a protective mechanism of APP}

The deficits in $\mathrm{APP}^{-1-}$ mice are clearly linked to calcium homeostasis, as shown by the complete rescue after preincubation with nifedipine. In line with these findings, calcium imaging revealed that the L-type calcium channel blocker did indeed decrease the hypoxia-induced calcium influx to WT levels. It is important to note that, in these experiments, WT slices were also treated with nifedipine and did not show any difference to drug-naive WT slices. Thus, L-type calcium channels do indeed account for the difference between $\mathrm{APP}^{-1-}$ and WT, rather than being an unspecific target for alleviating hypoxic damage. Indeed, APP has been shown to interact with $\mathrm{Ca}_{\mathrm{v}} 1.2$ LTCC and to suppress voltagedependent calcium influx into neurons (Yang et al., 2009). It is, thus, well possible that neurons lacking APP suffer increased calcium entry during hypoxia, followed by decreased E/S coupling. Increased calcium influx through LTCC contributes to cellular dysfunction in neurodegenerative disorders, such as $\mathrm{AD}$, in aging and ischemia/hypoxia induced cell death (Zhang et al., 2002; Thi- bault et al., 2007). Moreover, and in line with our findings, blockers of calcium channels appear to be promising neuroprotective drugs in $\mathrm{AD}$ (Anekonda and Quinn, 2011).

\section{Neuroprotective role of the soluble extracellular APP fragment}

Previous work has shown that many of the deficits induced by lack of APP can be rescued by selective expression of APPs $\alpha$ (Ring et al., 2007; Hick et al., 2015). Furthermore, APPs $\alpha$ was found to oppose toxic effects of amyloid $\beta$ (Obregon et al., 2012; Fol et al., 2016) and to exert neuroprotective effects in hypoxia-ischemia and traumatic brain injury. In our experiments, APPs $\alpha$-KI largely normalized the hypoxia-induced functional deficits, including the increased calcium influx. Whereas amyloid $\beta$ disrupts calcium homeostasis via upregulation of LTCC membrane levels (Webster et al., 2006), our study indicates an opposite, calcium-stabilizing role of full-length APP and/or the APPs $\alpha$ fragment by inhibition of calcium influx through LTCC. The effect of the extracellularly secreted APPs $\alpha$ on LTCC may be exerted via ligand-like receptor binding, in contrast to intracellular interaction of APP and LTCC as suggested by Yang et al. (2009). In our experimental approach, interactions with NMDA receptors do not contribute to the protective effects of APP. We also found no evidence for increased cell death in $\mathrm{APP}^{-1-}$ tissue compared with WT, both for pyramidal cells as well as for parvalbumin-expressing interneurons. The acute deficits in slices from $\mathrm{APP}^{-1-}$ mice do, therefore, appear to be caused by functional, rather than structural, alterations. It is well feasible that prolonged windows of observation in vivo would reveal delayed neuronal death (Kirino et al., 1992; Martin et al., 1994) but were not detected under acute conditions.

\section{Implications for ischemia and neurodegeneration}

The protective role of APP and APPs $\alpha$ via control of L-type calcium channels may also be relevant for chronic neurodegeneration. Indeed, dysregulation of cellular calcium homeostasis (Green and LaFerla, 2008; Berridge, 2010) and impaired energy metabolism (de la Torre, 2002) have been suggested as pathological mechanisms in $\mathrm{AD}$. On the other hand, overexpression of APP, as well as its molecular alteration or increased cleavage, leads to amyloid overloads. Animal models of Alzheimer's disease, based on APP mutations observed in familiar AD, do also show disturbed calcium homeostasis (Smith et al., 2005) and increased vulnerability to excitotoxicity (Palop et al., 2007). Thus, APP-mediated protection against hypoxia-induced functional loss and cell damage may follow a U-shaped curve, such that lack of APP is equally adverse as overexpression of mutated APP or its cleavage products.

In conclusion, we show a protective activity of APP and APPs $\alpha$ against hypoxia-induced loss of neuronal function. This effect may constitute a link between pathological mechanisms in $\mathrm{AD}$ as well as in vascular disease (Attems and Jellinger, 2014). Reconstituting calcium homeostasis under metabolic stress may be a fruitful target for new therapeutic strategies in both $\mathrm{AD}$ and hypoxic-ischemic brain damage.

\section{References}

Aitken PG, Tombaugh GC, Turner DA, Somjen GG (1998) Similar propagation of SD and hypoxic SD-like depolarization in rat hippocampus recorded optically and electrically similar propagation of SD and hypoxic SD-like depolarization in rat hippocampus recorded optically and electrically. J Neurophysiol 80:1514-1521. Medline

Anekonda TS, Quinn JF (2011) Calcium channel blocking as a therapeutic 
strategy for Alzheimer's disease: the case for isradipine. Biochim Biophys Acta 1812:1584-1590. CrossRef Medline

Attems J, Jellinger KA (2014) The overlap between vascular disease and Alzheimer's disease: lessons from pathology. BMC Med 12:206. CrossRef Medline

Aydin D, Weyer SW, Müller UC (2012) Functions of the APP gene family in the nervous system: insights from mouse models. Exp Brain Res 217: 423-434. CrossRef Medline

Bahmani P, Schellenberger E, Klohs J, Steinbrink J, Cordell R, Zille M, Müller J, Harhausen D, Hofstra L, Reutelingsperger C, Farr TD, Dirnagl U, Wunder A (2011) Visualization of cell death in mice with focal cerebral ischemia using fluorescent annexin A5, propidium iodide, and TUNEL staining. J Cereb Blood Flow Metab 31:1311-1320. CrossRef Medline

Bähner F, Weiss EK, Birke G, Maier N, Schmitz D, Rudolph U, Frotscher M, Traub RD, Both M, Draguhn A (2011) Cellular correlate of assembly formation in oscillating hippocampal networks in vitro. Proc Natl Acad Sci U S A 108:E607-E616. CrossRef Medline

Berridge MJ (2010) Calcium hypothesis of Alzheimer's disease. Eur J Physiol 459: 441-449. CrossRef Medline

Both M, Bähner F, von Bohlen und Halbach O, Draguhn A (2008) Propagation of specific network patterns through the mouse hippocampus. Hippocampus 18:899-908. CrossRef Medline

Burgess N, Maguire EA, O'Keefe J (2002) The human hippocampus and spatial and episodic memory. Neuron 35:625-641. CrossRef Medline

Buzsáki G, Draguhn A (2004) Neuronal oscillations in cortical networks. Science 304:1926-1929. CrossRef Medline

Cantrell AR, Catterall WA (2001) Neuromodulation of $\mathrm{Na}^{+}$channels: an unexpected form of cellular plasticity. Nat Rev Neurosci 2:397-407. CrossRef Medline

Clarke J, Thornell A, Corbett D, Soininen H, Hiltunen M, Jolkkonen J (2007) Overexpression of APP provides neuroprotection in the absence of functional benefit following middle cerebral artery occlusion in rats. Eur J Neurosci 26:1845-1852. CrossRef Medline

Cousins SL, Hoey SE, Anne Stephenson F, Perkinton MS (2009) Amyloid precursor protein 695 associates with assembled NR2A- and NR2Bcontaining NMDA receptors to result in the enhancement of their cell surface delivery. J Neurochem 111:1501-1513. CrossRef Medline

Csicsvari J, Hirase H, Czurkó A, Mamiya A, Buzsáki G (1999) Oscillatory coupling of hippocampal pyramidal cells and interneurons in the behaving Rat. J Neurosci 19:274-287. Medline

de la Torre JC (2002) Vascular basis of Alzheimer's pathogenesis. Ann N Y Acad Sci 977:196-215. CrossRef Medline

Dohmen C, Sakowitz OW, Fabricius M, Bosche B, Reithmeier T, Ernestus RI, Brinker G, Dreier JP, Woitzik J, Strong AJ, Graf R (2008) Spreading depolarizations occur in human ischemic stroke with high incidence. Ann Neurol 63:720-728. CrossRef Medline

Dreier JP, Major S, Manning A, Woitzik J, Drenckhahn C, Steinbrink J, Tolias C, Oliveira-Ferreira AI, Fabricius M, Hartings JA, Vajkoczy P, Lauritzen M, Dirnagl U, Bohner G, Strong AJ (2009) Cortical spreading ischaemia is a novel process involved in ischaemic damage in patients with aneurysmal subarachnoid haemorrhage. Brain 132:1866-1881. CrossRef Medline

Fol R, Braudeau J, Ludewig S, Abel T, Weyer SW, Roederer JP, Brod F, Audrain M, Bemelmans AP, Buchholz CJ, Korte M, Cartier N, Müller UC (2016) Viral gene transfer of APPs $\alpha$ rescues synaptic failure in an Alzheimers disease mouse model. Acta Neuropathol 131:247-266. CrossRef Medline

Foster KA, Beaver CJ, Turner DA (2005) Interaction between tissue oxygen tension and NADH imaging during synaptic stimulation and hypoxia in rat hippocampal slices. Neuroscience 132:645-657. CrossRef Medline

Garaschuk O, Milos RI, Konnerth A (2006) Targeted bulk-loading of fluorescent indicators for two-photon brain imaging in vivo. Nat Protoc 1:380-386. CrossRef Medline

Green KN, LaFerla FM (2008) Linking calcium to Abeta and Alzheimer's disease. Neuron 59:190-194. CrossRef Medline

Hick M, Herrmann U, Weyer SW, Mallm JP, Tschäpe JA, Borgers M, Mercken M, Roth FC, Draguhn A, Slomianka L, Wolfer DP, Korte M, Müller UC (2015) Acute function of secreted amyloid precursor protein fragment APPs $\alpha$ in synaptic plasticity. Acta Neuropathol 129:21-37. CrossRef Medline

Hoyer A, Bardenheuer HJ, Martin E, Plaschke K (2005) Amyloid precursor protein (APP) and its derivatives change after cellular energy depletion: an in vitro study. J Neural Transm 112:239-253. CrossRef Medline
Huchzermeyer C, Berndt N, Holzhütter HG, Kann O (2013) Oxygen consumption rates during three different neuronal activity states in the hippocampal CA3 network. J Cereb Blood Flow Metab 33:263-271. CrossRef Medline

Kann O (2011) The energy demand of fast neuronal network oscillations: insights from brain slice preparations. Front Pharmacol 2:90. CrossRef Medline

Kann O, Papageorgiou IE, Draguhn A (2014) Highly energized inhibitory interneurons are a central element for information processing in cortical networks. J Cereb Blood Flow Metab 34:1270-1282. CrossRef Medline

Kirino T, Robinson HP, Miwa A, Tamura A, Kawai N (1992) Disturbance of membrane function preceding ischemic delayed neuronal death in the gerbil hippocampus. J Cereb Blood Flow Metab 12:408-417. CrossRef Medline

Klausberger T, Magill PJ, Márton LF, Roberts JD, Cobden PM, Buzsáki G, Somogyi P (2003) Brain-state- and cell-type-specific firing of hippocampal interneurons in vivo. Nature 421:844-848. CrossRef Medline

Kögel D, Deller T, Behl C (2012) Roles of amyloid precursor protein family members in neuroprotection, stress signaling and aging. Exp Brain Res 217:471-479. CrossRef Medline

Koike MA, Lin AJ, Pham J, Nguyen E, Yeh JJ, Rahimian R, Tromberg BJ, Choi B, Green KN, LaFerla FM (2012) APP knockout mice experience acute mortality as the result of ischemia. PLoS One 7:e42665. CrossRef Medline

Li ZW, Stark G, Götz J, Rülicke T, Gschwind M, Huber G, Müller U, Weissmann C (1996) Generation of mice with a 200-kb amyloid precursor protein gene deletion by Cre recombinase-mediated site-specific recombination in embryonic stem cells. Proc Natl Acad Sci U S A 93:6158-6162. CrossRef Medline

Liotta A, Rösner J, Huchzermeyer C, Wojtowicz A, Kann O, Schmitz D, Heinemann U, Kovács R (2012) Energy demand of synaptic transmission at the hippocampal Schaffer-collateral synapse. J Cereb Blood Flow Metab 32:2076-2083. CrossRef Medline

Lobner D, Lipton P (1993) Intracellular calcium levels and calcium fluxes in the CAl region of the rat hippocampal slice during in vitro ischemia: relationship to electrophysiological cell damage. J Neurosci 13:48614871. Medline

Maier N, Nimmrich V, Draguhn A (2003) Cellular and network mechanisms underlying spontaneous sharp wave-ripple complexes in mouse hippocampal slices. J Physiol 550:873-887. CrossRef Medline

Martin RL, Lloyd HG, Cowan AI (1994) The early events of oxygen and glucose deprivation: setting the scene for neuronal death? Trends Neurosci 17:251-257. CrossRef Medline

Mattson MP, Cheng B, Culwell AR, Esch FS, Lieberburg I, Rydel RE (1993) Evidence for excitoprotective and intraneuronal calcium-regulating roles for secreted forms of the $\beta$-amyloid precursor protein. Neuron 10: 243-254. CrossRef Medline

Milosch N, Tanriöver G, Kundu A, Rami A, François J, Baumkötter F, Weyer SW, Samanta A, Jäschke A, Brod F, Buchholz CJ, Kins S, Behl C, Müller UC, Kögel D (2014) Holo-APP and G-protein-mediated signaling are required for sAPPa-induced activation of the Akt survival pathway. Cell Death Dis 5:e1391. CrossRef Medline

Misonou H, Mohapatra DP, Menegola M, Trimmer JS (2005) Calcium- and metabolic state-dependent modulation of the voltage-dependent Kv2.1 channel regulates neuronal excitability in response to ischemia. J Neurosci 25:11184-11193. CrossRef Medline

Mullen RJ, Buck CR, Smith AM (1992) NeuN, a neuronal specific nuclear protein in vertebrates. Development 116:201-211. Medline

Nimmrich V, Maier N, Schmitz D, Draguhn A (2005) Induced sharp waveripple complexes in the absence of synaptic inhibition in mouse hippocampal slices. J Physiol 563:663-670. CrossRef Medline

O’Brien RJ, Wong PC (2011) Amyloid precursor protein processing and Alzheimer's disease. Annu Rev Neurosci 34:185-204. CrossRef Medline

Obregon D, Hou H, Deng J, Giunta B, Tian J, Darlington D, Shahaduzzaman M, Zhu Y, Mori T, Mattson MP, Tan J (2012) sAPP- $\alpha$ modulates $\beta$-secretase activity and amyloid- $\beta$ generation. Nat Commun 3:777. CrossRef Medline

Palop JJ, Chin J, Roberson ED, Wang J, Thwin MT, Bien-Ly N, Yoo J, Ho KO, Yu GQ, Kreitzer A, Finkbeiner S, Noebels JL, Mucke L (2007) Aberrant excitatory neuronal activity and compensatory remodeling of inhibitory hippocampal circuits in mouse models of Alzheimer's disease. Neuron 55:697-711. CrossRef Medline

Pfeiffer T, Draguhn A, Reichinnek S, Both M (2014) Optimized temporally deconvolved $\mathrm{Ca}^{2+}$ imaging allows identification of spatiotemporal activ- 
ity patterns of CA1 hippocampal ensembles. Neuroimage 94:239-249. CrossRef Medline

Price JL, Ko AI, Wade MJ, Tsou SK, McKeel DW, Morris JC (2001) Neuron number in the entorhinal cortex and CA1 in preclinical Alzheimer disease. Arch Neurol 58:1395-1402. CrossRef Medline

Reichinnek S, Künsting T, Draguhn A, Both M (2010) Field potential signature of distinct multicellular activity patterns in the mouse hippocampus. J Neurosci 30:15441-15449. CrossRef Medline

Ring S, Weyer SW, Kilian SB, Waldron E, Pietrzik CU, Filippov MA, Herms J, Buchholz C, Eckman CB, Korte M, Wolfer DP, Müller UC (2007) The secreted beta-amyloid precursor protein ectodomain APPs alpha is sufficient to rescue the anatomical, behavioral, and electrophysiological abnormalities of APP-deficient mice. J Neurosci 27:7817-7826. CrossRef Medline

Sanchez MM, Moghadam S, Naik P, Martin KJ, Salehi A (2011) Hippocampal network alterations in Alzheimer's disease and Down syndrome: from structure to therapy. J Alzheimers Dis 26:29-47. CrossRef Medline

Schmidt-Kastner R, Freund TF (1991) Selective vulnerability of the hippocampus in brain ischemia. Neuroscience 40:599-636. CrossRef Medline

Schurr A, Payne RS, Miller JJ, Rigor BM (1999) Study of cerebral energy metabolism using the rat hippocampal slice preparation. Methods 18: 117-126. CrossRef Medline

Smith IF, Green KN, LaFerla FM (2005) Calcium dysregulation in Alzheimer's disease: recent advances gained from genetically modified animals. Cell Calcium 38:427-437. CrossRef Medline

Smith P, Reid DB, Environment C, Palo L, Alto P, Smith PL (1979) A threshold selection method from gray-level histograms. Trans Syst Cybern 9:62-66. CrossRef

Smith-Swintosky VL, Pettigrew LC, Craddock SD, Culwell AR, Rydel RE, Mattson MP (1994) Secreted forms of beta-amyloid precursor protein protect against ischemic brain injury. J Neurochem 63:781-784. Medline

Somjen GG (2001) Mechanisms of spreading depression and hypoxic spreading depression-like depolarization. Physiol Rev 81:1065-1096. CrossRef Medline

Thibault O, Gant JC, Landfield PW (2007) Expansion of the calcium hypothesis of brain aging and Alzheimer's disease: minding the store. Aging Cell 6:307-317. CrossRef Medline
Thornton E, Vink R, Blumbergs PC, Van Den Heuvel C (2006) Soluble amyloid precursor protein alpha reduces neuronal injury and improves functional outcome following diffuse traumatic brain injury in rats. Brain Res 1094:38-46. CrossRef Medline

Van den Heuvel C, Blumbergs PC, Finnie JW, Manavis J, Jones NR, Reilly PL, Pereira RA (1999) Upregulation of amyloid precursor protein messenger RNA in response to traumatic brain injury: an ovine head impact model. Exp Neurol 159:441-450. CrossRef Medline

Verret L, Mann EO, Hang GB, Barth AM, Cobos I, Ho K, Devidze N, Masliah E, Kreitzer AC, Mody I, Mucke L, Palop JJ (2012) Inhibitory interneuron deficit links altered network activity and cognitive dysfunction in Alzheimer model. Cell 149:708-721. CrossRef Medline

Webster NJ, Ramsden M, Boyle JP, Pearson HA, Peers C (2006) Amyloid peptides mediate hypoxic increase of L-type $\mathrm{Ca}^{2+}$ channels in central neurones. Neurobiol Aging 27:439-445. CrossRef Medline

Weyer SW, Klevanski M, Delekate A, Voikar V, Aydin D, Hick M, Filippov M, Drost N, Schaller KL, Saar M, Vogt MA, Gass P, Samanta A, Jäschke A, Korte M, Wolfer DP, Caldwell JH, Müller UC (2011) APP and APLP2 are essential at PNS and CNS synapses for transmission, spatial learning and LTP. EMBO J 30:2266-2280. CrossRef Medline

Yang L, Wang Z, Wang B, Justice NJ, Zheng H (2009) Amyloid precursor protein regulates Cav1.2 L-type calcium channel levels and function to influence GABAergic short-term plasticity. J Neurosci 29:15660-15668. CrossRef Medline

Yu SP, Yeh CH, Sensi SL, Gwag BJ, Canzoniero LM, Farhangrazi ZS, Ying HS, Tian M, Dugan LL, Choi DW (1997) Mediation of neuronal apoptosis by enhancement of outward potassium current. Science 278:114-117. CrossRef Medline

Zhang C, Shen W, Zhang G (2002) N-Methyl-D-aspartate receptor and L-type voltage-gated $\mathrm{Ca}(2+)$ channel antagonists suppress the release of cytochrome $\mathrm{c}$ and the expression of procaspase- 3 in rat hippocampus after global brain ischemia. Neurosci Lett 328:265-268. CrossRef Medline

Zhang X, Le W (2010) Pathological role of hypoxia in Alzheimer's disease. Exp Neurol 223:299-303. CrossRef Medline

Zhang X, Herrmann U, Weyer SW, Both M, Müller UC, Korte M, Draguhn A (2013) Hippocampal network oscillations in APP/APLP2-deficient mice. PLoS One 8:e61198. CrossRef Medline 